Haus, R., Kappel, D., Arnold, G.. Planetary Space Science xxx, xxx-xxx (2014) Preprint

Doi: 10.1016/j.pss.2014.11.020

\title{
Lower atmosphere minor gas abundances as retrieved from Venus Express VIRTIS-M-IR data at $2.3 \mu \mathrm{m}$
}

\author{
Rainer Haus $^{a^{*}}$, David Kappel ${ }^{\mathrm{b}}$, Gabriele Arnold \\ ${ }^{a}$ Westfälische Wilhelms-Universität Münster, Institute for Planetology, Wilhelm-Klemm- \\ Str.10, 48149 Münster, Germany, rainer.haus@gmx.de \\ ${ }^{\mathrm{b}}$ German Aerospace Center (DLR), Institute of Planetary Research, Rutherfordstrasse 2, \\ 12489 Berlin, Germany, dkappel@gmx.net, gabriele.arnold@ dlr.de
}

\begin{abstract}
Minor gas abundances in the lower atmosphere of Venus' southern hemisphere are investigated using spectroscopic nightside measurements recorded by the Visible and InfraRed Thermal Imaging Spectrometer aboard ESA's Venus Express mission in the moderate spectral resolution infrared mapping channel (VIRTIS-M-IR, 1-5 $\mu \mathrm{m}$, FWHM=17 $\mathrm{nm})$. The entire usable data archive is utilized including only radiation spectra sampled at long detector exposure times ( $\geq 3.3 \mathrm{~s}$ ) during eight Venus solar days between April 2006 and October 2008. Combined radiative transfer and retrieval techniques (Haus et al., 2013; Haus et al., 2014) are applied for a simultaneous determination of total cloud opacity and $\mathrm{H}_{2} \mathrm{O}, \mathrm{CO}$, and OCS abundances from the $2.3 \mu \mathrm{m}$ atmospheric transparency window that sounds the altitude range between about 30 and $45 \mathrm{~km}$. A wavelength-dependent $\mathrm{CO}_{2}$ opacity correction is considered.

Zonal averages of $\mathrm{CO}$ abundances at $35 \mathrm{~km}$ increase by about $35 \%$ from $(22.9 \pm 0.8) \mathrm{ppmv}$ at equatorial latitudes to $(31.0 \pm 2.1) \mathrm{ppmv}$ at $65^{\circ} \mathrm{S}$ and then decrease to $(29.4 \pm 2.4) \mathrm{ppmv}$ at $80^{\circ} \mathrm{S}$ The \pm figures refer to the statistical variability of retrieved abundances. In accordance with earlier results, the observed latitudinal variation of tropospheric $\mathrm{CO}$ is consistent with a Hadley cell-like circulation. Dawn side CO abundances at high latitudes are slightly smaller than dusk side values by about 7\%. The latitudinal distribution of OCS at $35 \mathrm{~km}$ is anticorrelated with that of $\mathrm{CO}$, ranging from about $(1.15 \pm 0.2) \mathrm{ppmv}$ at $65^{\circ} \mathrm{S}$ to $(1.60 \pm 0.2)$ ppmv at low latitudes (poleward decrease of 28\%). Zonal averages of $\mathrm{H}_{2} \mathrm{O}$ abundances near $35 \mathrm{~km}$ slightly decrease toward the South Pole by about $10 \%$, and the hemispheric average is (32.0 \pm 1.3$)$ ppmv. A significant local time dependence of OCS and $\mathrm{H}_{2} \mathrm{O}$ is not observed. Detailed analyses of individual spectrum retrieval errors for different atmospheric models reveal that $\mathrm{CO}$ abundance results are reliable (error 4-7\%), while $\mathrm{H}_{2} \mathrm{O}$ and OCS results have lower confidence (errors $30-47 \%$ and $41-86 \%$, respectively). $\mathrm{SO}_{2}$ abundances cannot reliably be retrieved from VIRTIS-M-IR spectra.
\end{abstract}


Haus, R., Kappel, D., Arnold, G.. Planetary Space Science xxx, xxx-xxx (2014) Preprint

\section{Introduction}

It is known since the mid 1980s and early 1990s that infrared radiation from the lower atmosphere of Venus and the planetary surface may escape to space in some narrow transparency windows between strong carbon dioxide and water vapor absorption bands shortward of $2.5 \mu \mathrm{m}$ where the singlescattering albedo of the sulfuric acid clouds approaches unity (i.e. clouds completely scatter radiation but do not absorb it). This radiation is only detectable on the nightside of the planet, since multiple-scattering of solar radiation in the dense Venus clouds exceeds thermal radiation by several orders of magnitude. The 2.3 and $1.74 \mu \mathrm{m}$ windows were discovered by Allen and Crawford (1984), while $1.31,1.28,1.18$, and $1.10 \mu \mathrm{m}$ window radiation signatures were first described by Allen (1990). The $1.02 \mu \mathrm{m}$ surface window was discovered by the Galileo-NIMS team (Carlson et al., 1991), and additional surface windows at 0.85 and $0.90 \mu \mathrm{m}$ were observed in Cassini-VIMS spectra (Baines et al., 2000).

These windows provide information about deep and lower atmosphere minor gas composition (1.10-2.3 $\mu \mathrm{m})$ at altitudes between about 10 and $45 \mathrm{~km}$ as well as on surface properties (0.85-1.18 $\mu \mathrm{m})$. Minor gases that have emission signatures within one or more of the transparency windows $\left(\mathrm{H}_{2} \mathrm{O}, \mathrm{CO}, \mathrm{OCS}, \mathrm{SO}_{2}, \mathrm{HCl}, \mathrm{HF}\right)$ may have a non-negligible influence on atmospheric radiative properties below the cloud base. The investigation of their distribution variations with altitude and latitude is an important prerequisite for sophisticated studies on Venus' radiative energy balance, chemical and transport models, and lower atmosphere - surface interactions such as buffering and possible volcanism.

Early ground-based telescopic observations, radiative transfer modeling, and spectroscopic analyses of minor gas signatures were performed for example by Kamp et al. (1988), Kamp and Taylor (1990), Bézard et al. (1990), Crisp et al. (1989; 1991), Carlson et al. (1991), Pollack et al.
(1993), Collard et al. (1993), de Bergh et al. (1995), and Meadows and Crisp (1996). A review of this and other work that explored many structural details of the lower atmosphere below the cloud base down to the surface was supplied by Taylor et al. (1997). More recent ground-based observations were described by Marcq et al. (2005; 2006), Cotton et al. (2012), and Arney et al. (2014). Earth-based measurements, however, are restricted to a small range of longitudes every 18 months due to the Venus-Earth spin-orbit commensurability. The spatial and temporal coverage of the NIMS and VIMS measurements was comparatively small because of the short duration of their spacecrafts' flybys.

The Visible and Infrared Thermal Imaging Spectrometer VIRTIS (Drossart et al., 2007; Piccioni et al., 2007; Arnold et al., 2011; Arnold et al., 2012) aboard the European Venus Express (VEX) mission is the first orbital instrument that systematically investigates the nightside emission of the planet. VIRTIS provides for the first time a detailed remote exploration of the lower atmosphere and surface of Venus and opens up new possibilities to study the minor gas abundances on global scales. VIRTIS is a complex imaging spectrometer that combines two optical subsystems in one compact instrument. The Mapper (M) subsystem is divided into the channels IR (1.0-5.1 $\mu \mathrm{m})$ and VIS $(0.3-1.1 \mu \mathrm{m})$ that are dedicated to spectral mapping at moderate spectral sampling (IR about $10 \mathrm{~nm}$, VIS about $2 \mathrm{~nm}$ ). The High resolution subsystem $(\mathrm{H})$ is devoted to spectroscopy (spectral sampling of about $1.6 \mathrm{~nm}$ ) in the spectral range $2-5 \mu \mathrm{m}$ (Arnold et al., 2012).

VIRTIS-M-IR data have been recently extensively used for self-consistent retrievals of mesospheric temperature profiles (58-85 $\mathrm{km})$ and cloud structure between 48 and 75 $\mathrm{km}$ in the northern and southern hemisphere of Venus (Haus et al., 2013; 2014). The 2.3 $\mu \mathrm{m}$ transparency window has been utilized in the new retrieval procedures to calculate cloud mode 3 particle abundances in the lower cloud deck at around $55 \mathrm{~km}$. Measured 
Haus, R., Kappel, D., Arnold, G.. Planetary Space Science xxx, xxx-xxx (2014) Preprint

spectra in the whole spectral range of this window $(2.2-2.5 \mu \mathrm{m})$ are strongly influenced by cloud opacity, but the signatures of different spectral sub-ranges in the longwavelength part (2.3-2.5 $\mu \mathrm{m})$ additionally depend on minor gas abundances.

It is the goal of the present study to use the entire archive of VIRTIS-M-IR imaging data for the southern nightside hemisphere sampled at long detector exposure times ( $\geq 3.3$ s) during eight Venus solar days between April 2006 and October 2008 for simultaneous cloud opacity and minor gas abundance retrievals. A full $2.3 \mu \mathrm{m}$ window spectral modeling approach is applied. This was done before in a similar way by Tsang et al. (2008), but the authors used measurements from four orbits only. Another study by Tsang et al. (2009) was based on a band ratio technique $(2.30 / 2.32 \mu \mathrm{m})$ using VIRTIS-M-IR data obtained during Venus Express operations between April 2006 and November 2007. Present investigations thus allow for comparing the results of different approaches of data selection. In principle, VIRTIS-H spectra are better suited to derive gas abundances due to the higher spectral resolution of measurements, which is especially important for OCS and $\mathrm{SO}_{2}$ retrievals near $2.45 \mu \mathrm{m}$. This was investigated by Marcq et al. (2008). On the other hand, the spatial and temporal coverage of M-IR data and the signal-to-noise ratio especially at high latitudes are much better than for $\mathrm{H}$ data. Moreover, M-IR yields a much broader spectral coverage down to 1 $\mu \mathrm{m}$, thus encompassing the three transparency windows between 1.25 and 1.80 $\mu \mathrm{m}$ as well as the three windows shortward of $1.2 \mu \mathrm{m}$ that are especially useful to retrieve water vapor abundances near the surface and surface emissivity (Bézard et al., 2009; Haus and Arnold, 2010).

Section 2 describes the applied data selection procedures. Section 3 provides information on prerequisites for minor gas abundance retrievals with respect to initial temperature, minor gas, and cloud structure altitude profiles. Section 4 presents a short description of the retrieval algorithm that has been currently adapted to the data. An error analysis for minor gas abundance retrievals at $2.3 \mu \mathrm{m}$ is given, and results for $\mathrm{H}_{2} \mathrm{O}, \mathrm{CO}$, OCS, and $\mathrm{SO}_{2}$ are shown in form of zonal averages. Maps of $\mathrm{CO}$ abundance and corresponding standard deviations are visualized as functions of local time and latitude. The discussion section 5 compares the results with earlier findings and provides context and interpretation about atmospheric dynamical aspects.

\section{Data reduction and processing}

VIRTIS-M-IR data were collected between April 14th, 2006 and October 29th, 2008. Julian date difference corresponds to about 930 Earth days, the so-called 'mission period'. Since a Venus solar day encompasses 116.75 Earth days, eight Venus solar days were covered by VIRTIS measurements. An elaborated data preprocessing pipeline was applied that includes refinements of data calibration as well as new approaches for an effective straylight removal (Kappel et al., 2012).

Since the northern hemisphere pushbroom measurements provide only a sparse time and space coverage, the present study focuses on the southern hemisphere of Venus where apocenter mapping observations were performed. To ensure comparable statistical weights of data recorded at low and high latitudes, the measurements are sorted into bins according to a Lambert equal-area map projection such that each bin corresponds to a surface coverage of about 100x100 km². For each bin, typically 30 spectra at each spectrally resolved spatially two-dimensional image were acquired by the instrument. The average over these concurrently measured spectra is computed to achieve an increase of the $\mathrm{S} / \mathrm{N}$ ratio by a factor of about $5(\sim \sqrt{3} 3)$. The notations 'spectrum' or 'measurement' always refer to one of these averaged (binned) spectra in the following. The applied binning scheme yields about $5 \cdot 10^{6}$ spectra over the full mission period. 
Haus, R., Kappel, D., Arnold, G.. Planetary Space Science xxx, xxx-xxx (2014) Preprint

Generally, temporal and spatial variations of atmospheric features for a defined measurement time interval are sufficiently characterized by grid spacings of $\Delta \mathrm{LT}=0.5 \mathrm{~h}$ in local time (LT) direction (corresponding to 7.5 degrees subsolar longitude) and $\triangle \mathrm{LAT}=5^{\circ}$ in latitude (LAT) direction. A subsequent procedure now selects only those measurements that were recorded in the vicinity of these grid points such that the LT and LAT distances to a grid point do not exceed $0.1 \mathrm{~h}=0: 06 \mathrm{~h}$ and $1^{\circ}$, respectively. This choice of interval lengths is somewhat arbitrary, but it was used to avoid too strong basic data smoothing between adjacent main grid points. Thus, the vicinity of the grid point $\left(23: 00 \mathrm{~h}, 55^{\circ}\right)$ covers the intervals 22:54-23:06 $\mathrm{h}$ in LT direction and 49-51 ${ }^{\circ}$ in LAT direction for example. The LT interval length of $0.2 \mathrm{~h}$ corresponds to $3^{\circ}$ subsolar longitude. The same local time and latitude grid spacing technique was recently used for the retrieval of mesospheric temperature altitude profiles in the southern hemisphere of Venus (Haus et al., 2014).

VIRTIS-M-IR radiance spectra were recorded at different detector exposure times ET. They vary between 0.02 and 18 seconds. For the nightside, the majority of long exposure time (LET) data were recorded at $3.3 \mathrm{~s}$, while most of short exposure time (SET) data correspond to $0.36 \mathrm{~s}$. LET measurements are better suited to retrieve atmospheric and surface parameters shortward of $3 \mu \mathrm{m}$, since the signal-to-noise ratio is higher than for short exposures. LET data terminate near $4 \mu \mathrm{m}\left(2500 \mathrm{~cm}^{-1}\right)$ or at even shorter wavelengths due to detector saturation from dark current. This is not important for present $2.3 \mu \mathrm{m}$ transparency window analyses that exclusively use LET data. But when mesospheric temperature field investigations are intended, which are based on $4.3 \mu \mathrm{m} \quad \mathrm{CO}_{2}$ absorption band measurements (Haus et al., 2013; 2014), the use of SET data is required.

There are two other arguments related to methodical aspects that further reduce the number of usable radiance spectra. Lower atmosphere and surface signatures (e.g. at 2.3 and $1.02 \mu \mathrm{m})$ are not detectable at daylight conditions, since multiple-scattering of solar radiation in the thick clouds exceeds thermal radiation by three to four orders of magnitude. Thus, only nightside data at sunzenith angles larger than $98^{\circ}$ (to also exclude twilight) can be used. Current simulation algorithms are based on a plane-parallel atmospheric model that is only justified for small and moderate observation angles $\varphi_{\text {obs. }}$. It was shown by Haus et al. (2014) that a comparatively small variation of $\varphi_{\mathrm{obs}}$ for $\varphi_{\text {obs }}>60^{\circ}$ produces much larger radiance or brightness temperature changes than corresponding variations at smaller $\varphi_{\text {obs. }}$ Spectra that were measured at observation angles larger than $60^{\circ}$ (mainly at equatorial latitudes) are removed from the final application archive, therefore.

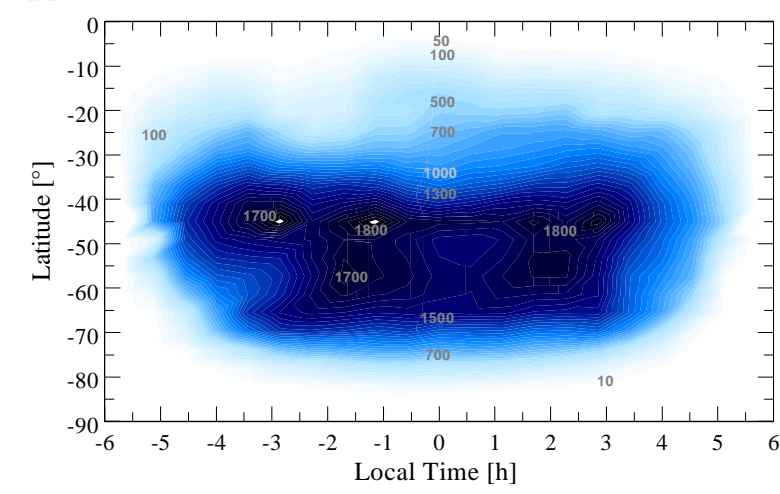

Figure 1. Post-selection spectra population in the local time and latitude space over the full mission period of VIRTIS-M-IR. Local time -5h corresponds to 19:00 h.

Figure 1 displays the distribution of spectra that were recorded over the full VIRTIS-MIR mission period considering the data reduction steps discussed above. Dark areas represent domains with large spectra population. Local time $-5 \mathrm{~h}$ for example stands for 5 hours before midnight, that is, 19:00 h. The numbers of spectra on the grid points range from zero to 1878 . The total number is about $2.6 \cdot 10^{5}$. The low spectrum population near the pole (especially near the beginning and end of night) is due to the above mentioned data restriction to sunzenith angles larger than $98^{\circ}$, because on Venus, polar regions are always close to a terminator.

The lower atmosphere minor gas composition is retrieved from the 
Haus, R., Kappel, D., Arnold, G.. Planetary Space Science xxx, xxx-xxx (2014) Preprint

atmospheric transparency window located at $2.3 \mu \mathrm{m}$ where different spectral sub-ranges between 2.3 and $2.5 \mu \mathrm{m}$ are particularly sensitive to different species. The utilized algorithm of simultaneous cloud parameter and minor gas abundance retrieval requires significant computing time. It is almost impossible, therefore, to process hundreds of thousands of individual spectra, and statistically reasonable spectra selections have to be performed in advance. For interpretation of corresponding results, retrieved parameters shall be averaged, and the corresponding standard deviations shall be calculated. This can be done in various ways. One can apply a random selection of $\mathrm{N}$ spectra at each grid point of the local time and latitude space. But statistically representative results are only obtained when $\mathrm{N}$ is sufficiently large. Present investigations use another spectra pre-selection method that has been described in detail by Haus et al. (2014), and only a short summary is given here.

The first processing step calculates the histogram of spectrum distribution for $5^{\circ}$ observation angle intervals at all grid points of the local time and latitude space. Let $\mathrm{GP}_{k}$ denote the k-th of these grid points. Only the interval for maximum spectrum population (the prevailing observation geometry) is selected at each $\mathrm{GP}_{\mathrm{k}}$ to avoid errors that may arise from an averaging of spectra that were measured at very different observation angles. In the second step, an initial radiance averaging is performed at each wavelength $\lambda$ of the $2.3 \mu \mathrm{m}$ window $(2.2-2.5 \mu \mathrm{m}, 4000$ $4550 \mathrm{~cm}^{-1}$ ). The resulting (artificial) radiance spectrum $\mathrm{R}_{\lambda}{ }^{\text {mean }}$ is used to calculate radiance standard deviations $\sigma_{\lambda}$. The notations $R_{\lambda}$ and $\sigma_{\lambda}$ are synonyms for spectra $R(\lambda)$ and $\sigma(\lambda)$, respectively. Sub-population fields are now specified, which comprise all elements that lie within $\pm 2 \sigma_{\lambda}$ from $\mathrm{R}_{\lambda}{ }^{\text {mean }}$ at each wavelength (i.e. about $95 \%$ of the full dataset assuming normal distribution). A real mean spectrum $\mathrm{R}_{\lambda}{ }^{\text {mean* }}$ is additionally determined that is in the least-squares sense the closest to $\mathrm{R}_{\lambda}{ }^{\text {mean }}$ over the full investigated spectral range. $\mathrm{R}_{\lambda}$ mean as an average over non-linear functions of cloud optical depth and minor gas abundances may not represent a realizable spectrum at all, but $\mathrm{R}_{\lambda}{ }^{\text {mean* }}$ is an actually measured spectrum representing an average state of the atmosphere at $\mathrm{GP}_{\mathrm{k}}$.

Some auxiliary spectra $\mathrm{R}_{\lambda}{ }^{\text {auxN }}$ are now selected from the above defined subpopulations. They shall explore the data variability at different spectral sub-ranges within the $2.3 \mu \mathrm{m}$ window. They are placed equidistantly in $\log \mathrm{R}$ in the intervals $\left[\mathrm{R}_{\lambda \mathrm{x}}{ }^{\text {mean }}, \mathrm{R}_{\lambda \mathrm{x}}{ }^{\mathrm{max}}\right]$ and $\left[\mathrm{R}_{\lambda \mathrm{x}}{ }^{\text {min }}, \mathrm{R}_{\lambda \mathrm{x}}{ }^{\text {mean }}\right]$ where $\mathrm{R}_{\lambda \mathrm{x}}{ }^{\text {max }}=\mathrm{R}_{\lambda \mathrm{x}}{ }^{\text {mean }}+2 \sigma_{\lambda \mathrm{x}}, \mathrm{R}_{\lambda \mathrm{x}}{ }^{\text {min }}=\mathrm{R}_{\lambda \mathrm{x}}{ }^{\text {mean }}-2 \sigma_{\lambda \mathrm{x}}$, and the wavelength $\lambda_{\mathrm{x}}$ is chosen close to the radiance maximum near $2.29 \mu \mathrm{m}$ (see Figure 2). 19 auxiliary spectra are defined in each of the two intervals excluding $\mathrm{R}_{\lambda \mathrm{x}}$ mean and including $\mathrm{R}_{\lambda x}{ }^{\max }$ or $\mathrm{R}_{\lambda x}{ }^{\min }$. Corresponding sets of real spectra $R_{\lambda}{ }^{\text {auxN* }}$ are subsequently determined according to the procedure used for $\mathrm{R}_{\lambda}{ }^{\text {mean }}$. Naturally, they are no longer forced to fulfill the demand of equidistance. It may occur that two or more of these spectra become identical. This consistently happens when a grid point in the local time and latitude space has a very sparse spectra population.

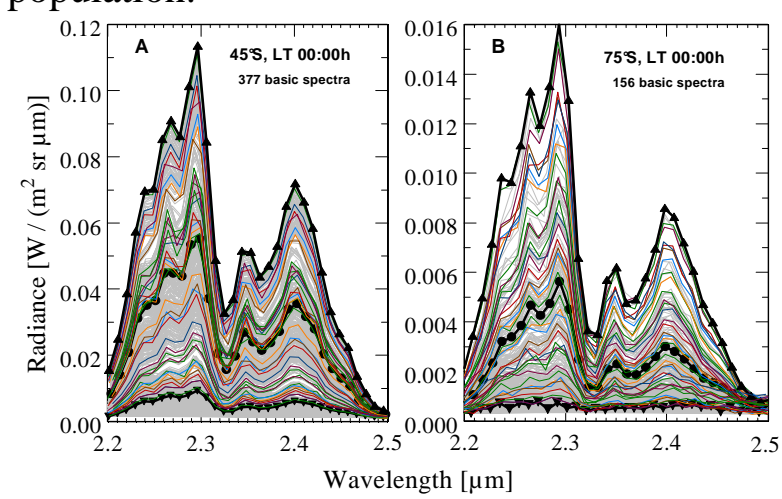

Figure 2. Spectra sub-populations (thin background lines) at $2.3 \mu \mathrm{m}\left(\mathrm{R}_{\lambda}{ }^{\text {mean }} \pm 2 \sigma_{\lambda}\right)$ at $45^{\circ} \mathrm{S}(\mathrm{A})$ and $75^{\circ} \mathrm{S}$ (B). Local time is midnight in both cases. Thick lines represent the 39 measured spectra that are basically selected for further processing. Solid circles: mean spectra $\mathrm{R}_{\lambda}{ }^{\text {mean* }}$, solid triangles down and up: minimum $\left(\mathrm{R}_{\lambda}{ }^{{ }^{\min *}}\right)$ and maximum $\left(\mathrm{R}_{\lambda}{ }^{\max *}\right)$ spectra.

Two examples for the described selection procedure are depicted in Figure 2 for the grid points at $45^{\circ} \mathrm{S} / 00: 00 \mathrm{~h}$ (display A) and $75^{\circ} \mathrm{S} /$ 00:00 h (display B) where 377 and 156 basic (artificial) spectra are available as results of the $\pm 2 \sigma_{\lambda}$ selection (thin lines). The thicker lines correspond to the real mean 
Haus, R., Kappel, D., Arnold, G.. Planetary Space Science xxx, xxx-xxx (2014) Preprint

$\left(\mathrm{R}_{\lambda}{ }^{{ }^{\text {mean }}{ }^{*}}\right)$ and the 38 auxiliary spectra $\left(\mathrm{R}_{\lambda}{ }^{\text {auxN*}}\right)$ described above.

Radiances decrease with increasing cloud opacity, but their spectral shape does not change significantly as long as opacity is not too large. But there were measurement situations where cloud opacity was extremely large ( $>50$, especially at polar latitudes, Figure 2B) and spectral signatures at $2.3 \mu \mathrm{m}$ became very small or even almost disappeared. Note the different radiance scales in displays A and B. The retrieval of minor gas abundances has turned out to be impossible in such a case (see Section 4.1). This is the reason why operational retrieval calculations are finally performed using only the 20 individual spectra from the upper spectrum set $\left\{\mathrm{R}_{\lambda}^{\text {mean* }^{*}}, \ldots, \mathrm{R}_{\lambda}{ }^{\text {max* }^{*}}\right\}$ at each grid point $\mathrm{GP}_{\mathrm{k}}$ of the local time and latitude space (one mean spectrum and 19 auxiliary spectra). Mean spectra $\mathrm{R}_{\lambda}{ }^{\text {mean* }}$ describe an average state of the atmosphere at $\mathrm{GP}_{\mathrm{k}}$, while the selected 19 auxiliary spectra are used to explore typical parameter variations at that grid point. In the 'worst case' when each grid point $\mathrm{GP}_{\mathrm{k}}$ would be fully populated, this selection procedure would still require a maximum of about 9,000 individual retrieval runs (18 latitudes $0-85^{\circ} \mathrm{S}, 25$ local times $18-6$ $\mathrm{h}, 20$ spectra) for a selected data acquisition time period. But this number is small compared with the total number of usable spectra (about $2 \cdot 6 \cdot 10^{5}$ ).

\section{Prerequisites for minor gas abundance retrieval}

A radiative transfer simulation model (RTM) is used to simulate observed VIRTIS-M-IR radiance spectra in dependence on atmospheric parameters. It has been described in detail in previous publications (Haus and Arnold, 2010; Haus et al., 2013; 2014). Present investigations exclusively use the spectral range of the $2.3 \mu \mathrm{m}$ atmospheric transparency window where cloud opacity and minor gas abundances are retrieved from. Initial atmospheric models required for RTM operation encompass altitude profiles of atmospheric temperature, minor gas abundances, and cloud mode particle densities. These models are used to calculate molecular and particulate absorption and scattering coefficients at defined levels of a plane-parallel atmosphere and top-ofatmosphere radiance spectra considering instrument specific parameters such as spectral resolution. $\mathrm{A} \mathrm{CO}_{2}$ opacity correction, shortly referred to as 'continuum' in the following, is an important additional input parameter. It has been determined by Kappel et al. (2012) and Kappel (2014) applying a new multi-spectrum retrieval algorithm (MSR). MSR simultaneously utilizes information from thousands of spectra that originated from highly diverse physical and observational conditions on the planet. In contrast to locally varying atmospheric parameters such as cloud opacity and minor gas distribution, continuum absorption is a parameter that is the same for all spectra and therefore separable as retrieval parameter that is common to all utilized spectra. Present analyses use spectrally variable opacity correction values (Kappel et al., 2012) that do not only differ for different atmospheric transparency windows, but also vary with wavelength within a specific window. The corresponding spectrally averaged value for the $2.3 \mu \mathrm{m}$ window is $43 \cdot 10^{-9} \mathrm{~cm}^{-1}$ amagat $^{-2}$ (Haus et al., 2013). For comparison, a constant value of $35 \cdot 10^{-9} \mathrm{~cm}^{-1}$ amagat $^{-2}$ was used by Bézard et al. (1990), Pollack et al. (1993), Marcq et al. (2008), and Tsang et al. (2008), while Tsang et al. (2009) used 40 10${ }^{9} \mathrm{~cm}^{-1}$ amagat ${ }^{-2}$.

\subsection{Temperature profiles}

Figure 3 shows initial temperature altitude profiles of Venus' nightside atmosphere. They are constructed from latitude-dependent VIRA-2 temperature profiles between 50 and $90 \mathrm{~km}$ (Zasova et al., 2006) and VIRA-1 profiles (Seiff et al., 1985) between 0 and 40 $\mathrm{km}$, which are latitude-independent below 32 $\mathrm{km}$ from the outset. Linear interpolations connect VIRA-2 values at $50 \mathrm{~km}$ and VIRA1 values at $40 \mathrm{~km}$, and linear interpolations are also used to an assumed latitudeindependent night time profile ('N') above 
Haus, R., Kappel, D., Arnold, G.. Planetary Space Science xxx, xxx-xxx (2014) Preprint

$90 \mathrm{~km}$. The horizontal line at $58 \mathrm{~km}$ indicates the approximate VIRTIS-M-IR lower temperature sounding level in the $4.3 \mu \mathrm{m}$ $\mathrm{CO}_{2}$ absorption band.

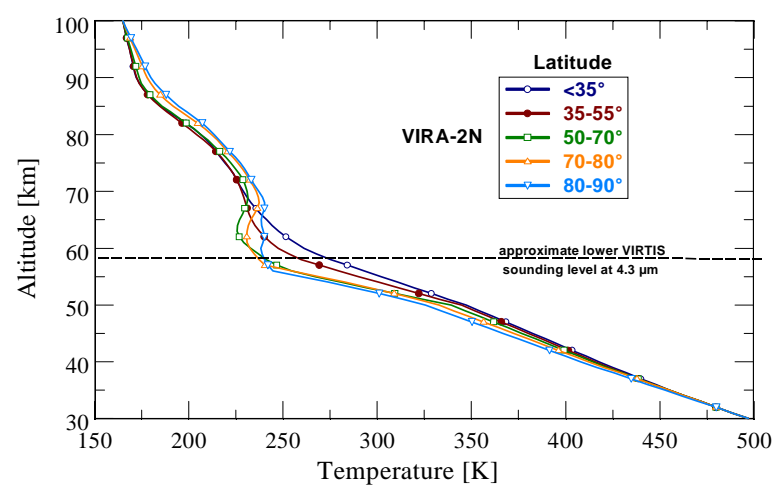

Figure 3. VIRA-2N averaged temperature profiles for different latitude ranges.

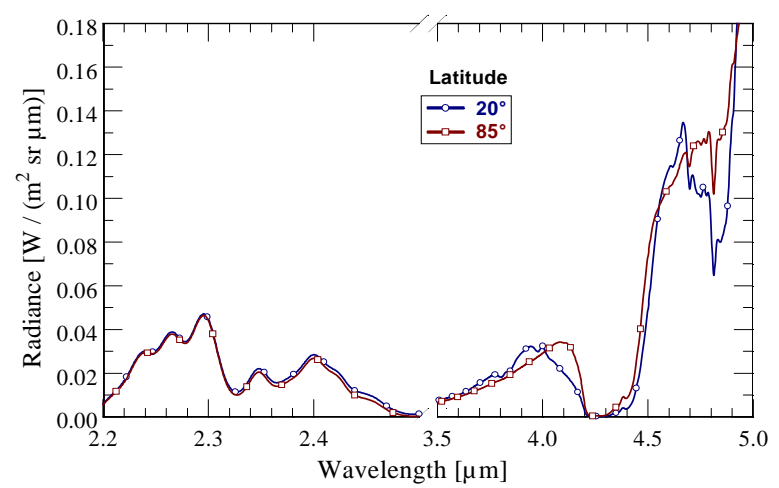

Figure 4. Simulated VIRTIS-M-IR radiance spectra for VIRA-2N temperature profiles at latitudes $20^{\circ}$ and $85^{\circ}$.

Figure 4 displays RTM simulation results for $20^{\circ} \mathrm{S}$ and $85^{\circ} \mathrm{S}$ using the appropriate temperature profiles from Figure 3 and minor gas and cloud mode altitude distributions according to the initial models described below in Sections 3.2 and 3.3. The $4.3 \mu \mathrm{m}$ $\mathrm{CO}_{2}$ absorption band sounds the altitude region of about 58-90 $\mathrm{km}$ where upper cloud (57-70 km) and overlying haze layers (70-90 $\mathrm{km})$ are located. This band was recently used by Haus et al. $(2013 ; 2014)$ to retrieve the mesospheric temperature fields from VIRTIS-M-IR measurements. Radiances strongly respond to temperature changes in this altitude range. Below $58 \mathrm{~km}$, temperature weighting functions become very small and the temperature retrieval procedure tends to reproduce values given by the initial temperature model. Recall that mesospheric temperature retrievals are not possible from currently used long exposure time (LET)-VIRTIS data.

Maximum response to lower atmosphere temperature changes in the spectral range of the $2.3 \mu \mathrm{m}$ transparency window occurs in the altitude region below the main cloud deck at about 27-35 km (Haus and Arnold, 2010). Due to small differences of the $20^{\circ}$ and $85^{\circ}$ temperature profiles at altitudes below 40 $\mathrm{km}$, temperature induced radiance changes at $2.3 \mu \mathrm{m}$ are very small. The long-wavelength shoulder shows a slightly higher response, while radiances in the short-wavelength shoulder remain nearly unchanged. This was also discussed before by Collard et al. (1993). There are almost no spectral features regarding differences of the two curves at around $2.3 \mu \mathrm{m}$, and temperature and cloud opacity influences cannot be separated, therefore. This is another reason why temperature profile retrieval is not possible at $2.3 \mu \mathrm{m}$. Moreover, the small number of measurement data points between 2.2 and 2.3 $\mu \mathrm{m}$ (about ten) would not allow achieving satisfactory altitude resolution of temperature structure. This discussion clarifies that latitude-dependent VIRA-2N initial temperature models provide an adequate input for lower atmosphere minor gas distribution studies.

\subsection{Initial minor gas distribution}

Figure 5 shows initial minor gas altitude distributions that essentially correspond to those given by Tsang et al. (2008). The main gaseous constituent $\mathrm{CO}_{2}$ has a vertically uniform volume mixing ratio of $9.65 \cdot 10^{5}$ ppmv. Water vapor $\left(\mathrm{H}_{2} \mathrm{O}\right)$ and sulfur dioxide $\left(\mathrm{SO}_{2}\right)$ are assumed to be uniformly mixed in the lower atmosphere below $50 \mathrm{~km}$ with volume mixing ratios of 32.5 and $150 \mathrm{ppmv}$, respectively. Carbon monoxide $(\mathrm{CO})$ and carbonyl sulfide (OCS) are modeled to have a constant mixing ratio of 20 and 15 ppmv below about $30 \mathrm{~km}$. CO abundance increases to about $50 \mathrm{ppmv}$ at $60 \mathrm{~km}$, but OCS abundance quickly drops down to $0.05 \mathrm{ppmv}$ at this altitude. $\mathrm{CO}$ enhancement at altitudes above $70 \mathrm{~km}$ is due to the photolysis of $\mathrm{CO}_{2}$ 
Haus, R., Kappel, D., Arnold, G.. Planetary Space Science xxx, xxx-xxx (2014) Preprint

by UV radiation above the cloud tops. The hydrogen halides $(\mathrm{HCl}, \mathrm{HF})$ are assumed to be uniformly mixed with mixing ratios of 500 and 5 ppbv, respectively.

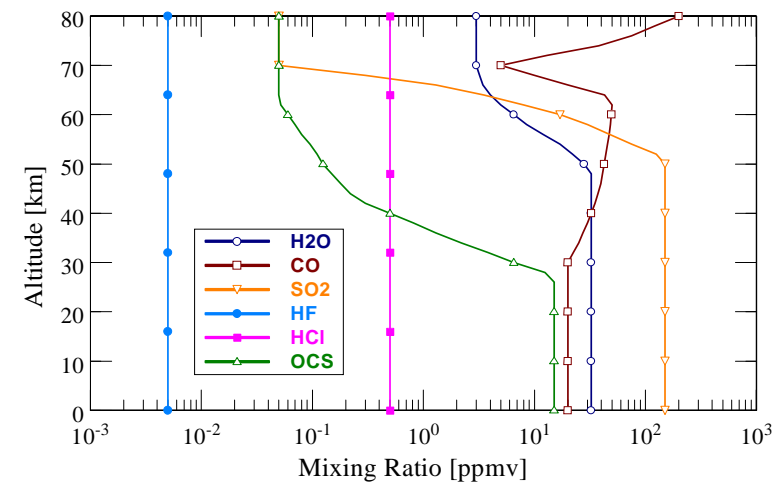

Figure 5. Initial model of volume mixing ratios of minor constituents.

Present investigations of minor gas abundances focus on the lower atmosphere of Venus below $45 \mathrm{~km}$. This altitude domain is sounded by the $2.3 \mu \mathrm{m}$ window. Its longwavelength shoulder yields information on $\mathrm{H}_{2} \mathrm{O}, \mathrm{CO}, \mathrm{OCS}$, and $\mathrm{SO}_{2}$ abundances. Figure $\underline{6}$ displays RTM simulation results for gas column abundance variations. A so-called gas factor ' $\mathrm{GF}_{\mathrm{i}}$ ' modifies the initial gas $\mathrm{i}$ mixing ratio profile described in Figure 5 at all atmospheric levels, i.e., it changes the total atmospheric column density of that gas. The VIRA-2N temperature profile at $45^{\circ}$ and the initial cloud mode distributions (Section 3.3) are used. Figure 6A shows radiance spectra for the standard case where all gas factors are unity $\left(\mathrm{GF}_{\mathrm{i}}=1.0\right)$ and for an increase of single gas factors by $30 \%$ $\left(\mathrm{GF}_{\mathrm{i}}=1.3\right)$, while Figure $6 \mathrm{~B}$ illustrates radiance ratios $R_{\mathrm{i}}:=\mathrm{R}_{\mathrm{i}} / \mathrm{R}_{\mathrm{i} 0}$ for an increase of single gas factors by $5 \%$ where $\mathrm{R}_{\mathrm{i} 0}$ and $\mathrm{R}_{\mathrm{i}}$ are the radiances for $\mathrm{GF}_{\mathrm{i}}=1.0$ and $\mathrm{GF}_{\mathrm{i}}=1.05$, respectively.

It is important to note that the shortwavelength shoulder of the $2.3 \mu \mathrm{m}$ window is not influenced by minor gas abundance variations, while signatures of the whole window strongly depend on cloud opacity changes (see Section 3.3). This is the most crucial premise that enables minor gas retrievals at $2.3 \mu \mathrm{m}$, since cloud influence can be well separated. CO can be detected between 2.30 and $2.42 \mu \mathrm{m}$, but signatures longward of $2.34 \mu \mathrm{m}$ are obscured by $\mathrm{H}_{2} \mathrm{O}$.
$\mathrm{H}_{2} \mathrm{O}$ is best detectable at $2.42 \mu \mathrm{m}$. It overlaps with OCS and $\mathrm{SO}_{2}$ longward of $2.43 \mu \mathrm{m}$. $\mathrm{SO}_{2}$ will be difficult to retrieve from VIRTIS-M-IR measurements due to its very weak band, its narrow spectral range around $2.47 \mu \mathrm{m}$ (only two or three VIRTIS-M-IR measurement data points), and its overlap with OCS and $\mathrm{H}_{2} \mathrm{O}$. It is already difficult to recognize the impact of the $30 \% \quad \mathrm{SO}_{2}$ abundance change in Figure 6A.

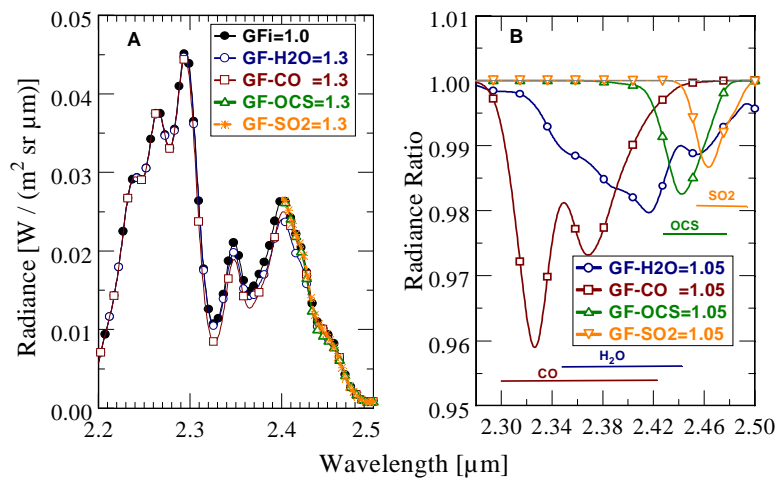

Figure 6. Simulated VIRTIS-M-IR radiance spectra (A) and radiance ratios (B) at $2.3 \mu \mathrm{m}$ for different gas abundance factors GF. Horizontal lines in display B indicate the regions where the spectrum is sensitive to minor gas abundance changes.

The effective altitude range of minor gas $\mathrm{i}$ distribution sounding can be derived from wavelength-dependent weighting functions $\mathrm{W}_{\mathrm{i} \lambda}$. They are determined by changing the gas mixing ratio $\mathrm{Q}_{i}\left(\mathrm{z}_{\mathrm{j}}\right)$ of a single layer $\mathrm{j}$ at mean altitude $\mathrm{z}_{\mathrm{j}}$ by a defined amount $\delta \mathrm{Q}_{\mathrm{i}}\left(\mathrm{z}_{\mathrm{j}}\right)$ and calculating the top-of-atmosphere radiance difference quotients $\delta \mathrm{R}_{\lambda} / \delta \mathrm{Q}_{\mathrm{i}}$ with respect to this variation for all layers $\mathrm{j}$. This is illustrated in Figure 7 where the midlatitude VIRA-2N temperature profile (cf. Figure 3) and the initial cloud model described in Section 3.3 are used for $\mathrm{W}_{\mathrm{i} \lambda}$ calculation. The grey background arrays of curves roughly encompass the gas specific sensitive wavelength ranges marked by the horizontal lines in Figure 6B. The altitudes of $\mathrm{W}_{\mathrm{i} \lambda}$ peaks (as indicated by the z-column in the small tables in each display) correspond to the altitudes where the measured top-ofatmosphere radiances are most sensitive at that wavelength to the respective gas mixing ratio. This is highlighted for some selected wavelengths by the thick curves in the figure that peak at altitudes between 34 and $43 \mathrm{~km}$. 
Haus, R., Kappel, D., Arnold, G.. Planetary Space Science xxx, xxx-xxx (2014) Preprint

Retrieval results for $\mathrm{CO}$ and $\mathrm{H}_{2} \mathrm{O}$ gas factors will mostly reflect abundance changes at altitudes between 35 and $37 \mathrm{~km}$ (displays 7A and 7B). OCS will be also retrieved at around $35 \mathrm{~km}$ (display C), while possibly detectable $\mathrm{SO}_{2}$ changes are mainly valid for altitudes 41-43 km (display D). If, for example, a water vapor factor of 1.2 would be retrieved, this would mean that the $\mathrm{H}_{2} \mathrm{O}$ mixing ratio at $35 \mathrm{~km}$ is 39 instead of $32.5 \mathrm{ppmv}$ as given by the initial model in Figure 5. This does not necessarily mean, however, that the near surface mixing ratio is also as high as 39 ppmv.

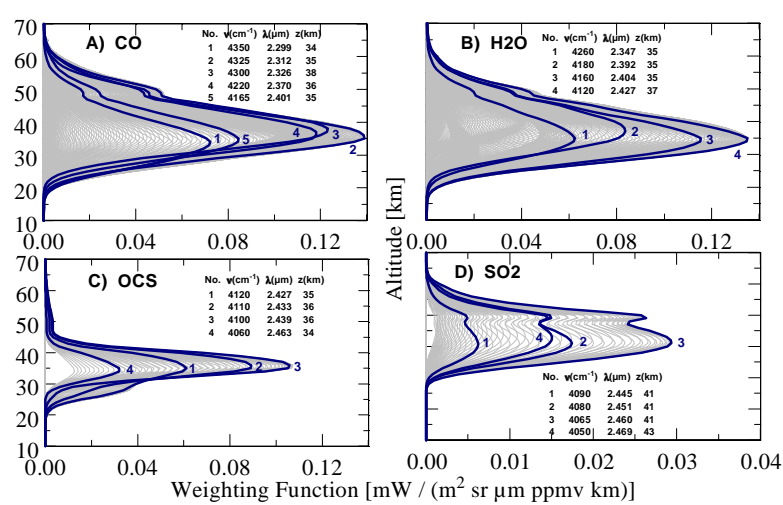

Figure 7. Minor gas abundance weighting functions W in the $2.3 \mu \mathrm{m}$ window (gray background lines) and W's for selected wavelengths (thick solid lines).

Pollack et al. (1993) have shown that a much better fit to the spectral region from 2.42 to $2.46 \mu \mathrm{m}$ can be achieved when the OCS mixing ratio is allowed to increase sharply with decreasing altitude across the sensing region around $35 \mathrm{~km}$. The authors were unable to fit the measurements for any constant mixing ratio. No attempt was made in the present study to retrieve a vertical gradient that differs from the initial OCS distribution (cf. Figure 5) where this steep gradient is already considered.

$\mathrm{H}_{2} \mathrm{O}$ abundance changes in the deep atmosphere may also affect signatures of the three transparency windows located at 1.74, 1.18, and $1.10 \mu \mathrm{m}$. The $\mathrm{H}_{2} \mathrm{O}$ weighting function maximum at $1.74 \mu \mathrm{m}$ occurs at 23 $\mathrm{km}$, while the two other windows sound the altitude range at about $10 \mathrm{~km} . \mathrm{H}_{2} \mathrm{O}$ retrieval from these three windows is very difficult, however. The $1.74 \mu \mathrm{m}$ window peak is influenced both by $\mathrm{H}_{2} \mathrm{O}$ and $\mathrm{HCl}$ variations.
At VIRTIS-M-IR resolution, the two species can neither be separated from each other nor from cloud influences. $\mathrm{H}_{2} \mathrm{O}$ is the only minor gas that may significantly modify radiances in the 1.10 and $1.18 \mu \mathrm{m}$ windows (Bézard et al., 2009; 2011). But together with the 1.02 $\mu \mathrm{m}$ signature, these windows may be significantly influenced by surface emissivity changes. These are the reasons why no attempt is made in the present study to retrieve water vapor from the $1.74,1.18$, and $1.10 \mu \mathrm{m}$ windows.

\subsection{Cloud mode particle distribution}

Figure 8 illustrates the initial cloud mode particle distribution with altitude proposed by Haus et al. (2013). The usual assumption for modeling purposes is that there are four particle size modes that consist of $75 \%$ weight-percent $\mathrm{H}_{2} \mathrm{SO}_{4}$ aerosols (e.g. Pollack et al., 1993; Zasova et al., 2007; Tsang et al., 2008; Haus and Arnold, 2010; Haus et al., 2013).

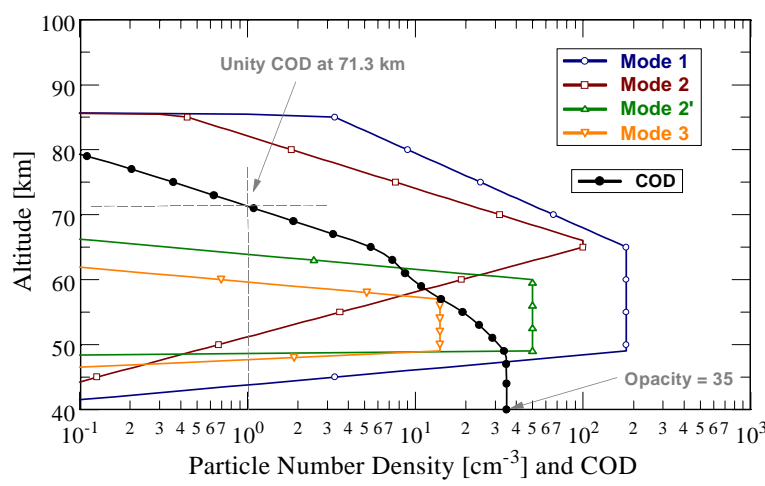

Figure 8. Particle number density distribution functions of the initial cloud model (Haus et al., 2013). COD: Cumulative cloud optical depth at $1 \mu \mathrm{m}$.

To calculate cloud absorption and scattering cross-sections and resulting optical depths, log-normal size distributions are used for all four modes with modal radii of $0.3,1.0,1.4$, $3.65 \mu \mathrm{m}$ and unitless dispersions of 1.56 , $1.29,1.23,1.28$, respectively (Pollack et al., 1993). An updated refractive index database for $\mathrm{H}_{2} \mathrm{SO}_{4}$ aerosols is utilized that is based on laboratory measurements performed by Palmer and Williams (1975) and Carlson and Anderson (2011), see Haus et al. (2013). This initial cloud model yields a cumulative optical depth (COD) of unity at $71.3 \mathrm{~km}$ and 
Haus, R., Kappel, D., Arnold, G.. Planetary Space Science xxx, xxx-xxx (2014) Preprint

$1 \mu \mathrm{m}$. The altitude of unity optical depth is usually denoted as 'cloud top altitude'. Since aerosol microphysical parameters are functions of wavelength according to their refractive index specifics, any optical depth and cloud top altitude results have to be referenced to wavelength (usually $1 \mu \mathrm{m}$ ). The total initial model COD of the cloud deck (opacity) is 35.0 at $1.0 \mu \mathrm{m}$. This value is also attained at a wavelength of $2.276 \mu \mathrm{m}$ that can serve as a proxy for the $1.0 \mu \mathrm{m}$ value within the $2.3 \mu \mathrm{m}$ window, therefore (cf. Figure 9).

Cloud optical depth variations are modeled in present radiative transfer simulations by variation of particle number densities. The densities can be varied independently for each cloud mode $\mathrm{i}$ by use of a so-called cloud mode factor $\mathrm{MF}_{\mathrm{i}}$, but maintaining the altitude distribution that is determined by the initial cloud model (Haus et al., 2012; 2013). This approach is well suited to fit measured radiance spectra over a broad spectral range that includes two or more atmospheric windows. Present investigations exclusively make use of the $2.3 \mu \mathrm{m}$ window, and the determination of a total cloud factor $\mathrm{CF}$ for this window is sufficient. CF scales the particle number density profiles for all modes simultaneously. The sensitivity of retrieved gas abundances to assumed initial cloud parameters will be evaluated in Section 4.2.

Figure 9 shows RTM simulation results for different cloud factors CF between 0.8 and 2.0. The VIRA-2N temperature profile at $45^{\circ}$ and the initial minor gas altitude distributions are used. $\mathrm{CF}=1.5$ generates a $2.29 \mu \mathrm{m}$ peak radiance of about $4 \cdot 10^{-3} \mathrm{~W} /\left(\mathrm{m}^{2} \mathrm{sr} \mu \mathrm{m}\right)$ at VIRTIS-M-IR resolution that is close to the observed radiances $\mathrm{R}_{2.29}{ }^{\text {(mean-2)* }}, \mathrm{R}_{2.29}{ }^{\text {(mean-3)** }}$, and $\mathrm{R}_{\left.2.29^{(m e a n}-4\right)^{*}}$ at $2.29 \mu \mathrm{m}$ and $75^{\circ} \mathrm{S}$ (cf. Figure 2, display B). The notation (mean-N)* refers to the auxiliary spectrum number $\mathrm{N}^{*}$ that has lower radiances than the mean spectrum $\mathrm{R}_{\lambda}{ }^{\text {mean* }}$. The peak radiance at $\mathrm{CF}=2.0$ is about $5 \cdot 10^{-4} \mathrm{~W} /\left(\mathrm{m}^{2}\right.$ sr $\left.\mu \mathrm{m}\right)$. This value is close to the noise equivalent radiance of VIRTIS-M-IR data at this wavelength (and used detector exposure time) before binning. Minor gas abundance retrieval is not possible in this situation. The slowly varying line with crosses in Figure 9 reflects the spectral dependence of cloud opacity for $\mathrm{CF}=1.0$. The value of 35.0 (initial cloud opacity) is attained at 2.276 (and 1.0) $\mu \mathrm{m}$.

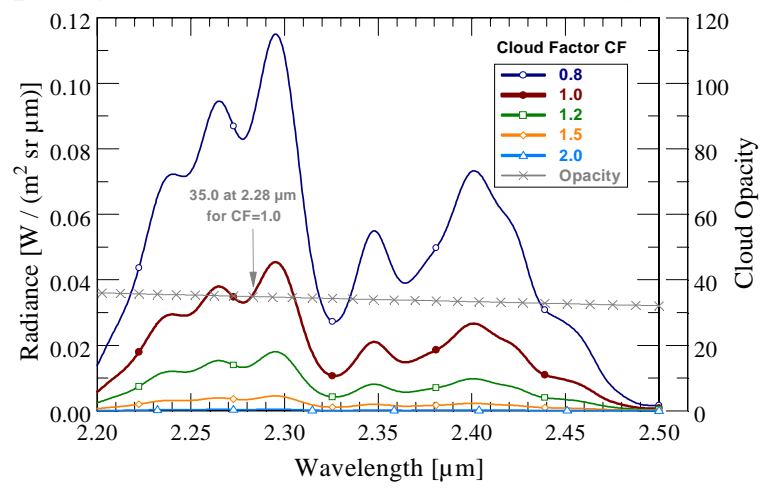

Figure 9. Simulated VIRTIS-M-IR radiance spectra at $2.3 \mu \mathrm{m}$ for different total cloud factors CF. The righthand scale refers to the total cloud opacity for $\mathrm{CF}=1.0$.

\section{Retrieval method and results}

The total cloud factor $\mathrm{CF}$ and minor gas column density factors $\mathrm{GF}_{\mathrm{i}}$ are simultaneously retrieved from different parts of the $2.3 \mu \mathrm{m}$ window by determination of least-squares best fits for measured VIRTISM-IR radiance spectra using an iterative algorithm. The short-wavelength shoulder of the $2.3 \mu \mathrm{m}$ window between 2.1 and $2.3 \mu \mathrm{m}$ is not influenced by minor gas abundance variations. It is used to retrieve $\mathrm{CF}$. Minor gas factors $\mathrm{GF}_{\mathrm{i}}$ are then determined from the long-wavelength shoulder of the window using the actual $\mathrm{CF}$ value. The gas factors modify the total atmospheric column density of $\mathrm{H}_{2} \mathrm{O}, \mathrm{CO}, \mathrm{OCS}$, and $\mathrm{SO}_{2} . \mathrm{GF}_{\mathrm{CO}}$ is determined at first from the spectral range 2.30-2.42 $\mu \mathrm{m}$, followed by the $\mathrm{GF}_{\mathrm{H} 2 \mathrm{O}}$ retrieval at 2.34-2.44 $\mu \mathrm{m}$. Since spectral fingerprints of the two species overlap (cf. Figure 6), additional iterations are performed. Satisfactory convergence is usually achieved after three iteration steps. Using the retrieved $\mathrm{H}_{2} \mathrm{O}$ and $\mathrm{CO}$ abundances, $\mathrm{GF}_{\mathrm{OCS}}(2.42-2.47$ $\mu \mathrm{m})$ and $\mathrm{GF}_{\mathrm{SO} 2}(2.45-2.49 \mu \mathrm{m})$ are iteratively determined in the following step. Due to very weak $\mathrm{SO}_{2}$ signatures, the accuracy of $\mathrm{SO}_{2}$ retrieval is quite low, however. The new parameters are eventually used to calculate 
Haus, R., Kappel, D., Arnold, G.. Planetary Space Science xxx, xxx-xxx (2014) Preprint

the radiance spectrum between 2.2 and 2.5 $\mu \mathrm{m}$ in order to verify the quality of the fit.

\subsection{Cloud factor influence on retrieved gas abundances}

Measured radiances in the $2.3 \mu \mathrm{m}$ window are very small when cloud opacity is extremely large, and it can be expected that minor gas abundance retrievals become impossible beyond a certain opacity level. This is illustrated in Figures 10 and 11. Figure 10 shows retrieved midnight gas abundances as functions of retrieved cloud factors at $45^{\circ} \mathrm{S}$ and $10^{\circ} \mathrm{S}$, while Figure 11 visualizes the corresponding results for $60^{\circ} \mathrm{S}$ and $75^{\circ} \mathrm{S}$. Depicted scatter points result from 39 retrievals (one mean and 38 auxiliary spectra, cf. Section 2) in each case. Mid latitudes are usually covered by thinner clouds compared with polar and equatorial latitudes (Haus et al., 2013; 2014). The retrieved cloud factors $\mathrm{CF}$ at 45, 10, 60, and $75^{\circ} \mathrm{S}$ are $0.93(0.77,1.32), 1.13(0.89,1.99)$, $1.03(0.88,1.36)$, and $1.46(1.23,1.88)$, respectively. Leading values refer to the mean spectrum $\mathrm{R}_{\lambda}{ }^{{ }^{\text {mean }} \text {, }}$, values in parentheses yield $C F$ values for the spectra $R_{\lambda}{ }^{\text {min* }^{*}}$ and $\mathrm{R}_{\lambda}{ }^{\text {max* }}$. Gas factors $\mathrm{GF}_{\mathrm{H} 2 \mathrm{O}}$ and $\mathrm{GF}_{\mathrm{CO}}$ at mid latitudes (Figure 10A) are obviously not correlated with the cloud factor. $\mathrm{GF}_{\mathrm{OCS}}$ and $\mathrm{GF}_{\mathrm{SO} 2}$ sharply decrease for $\mathrm{CF}>1.2$ (Figure 10B) and quickly reach a value of 0.4 that was arbitrarily fixed as the lower allowed boundary for all gas factor retrieval results. They also show a slight decrease between $\mathrm{CF}=1.0$ and $\mathrm{CF}=1.2$. At $10^{\circ} \mathrm{S}, \mathrm{GF}_{\mathrm{H} 2 \mathrm{O}}$ and $\mathrm{GF}_{\mathrm{CO}}$ remain quite independent on $\mathrm{CF}$ (Figure 10C), while $\mathrm{GF}_{\mathrm{OCS}}$ and $\mathrm{GF}_{\mathrm{SO} 2}$ again sharply decrease for $\mathrm{CF}>1.2$ (Figure 10D). Results for $60^{\circ} \mathrm{S}$ (Figures 11A and B) behave similar to $45^{\circ} \mathrm{S}$. Polar latitudes $\left(75^{\circ} \mathrm{S}\right.$ as an example here where $\mathrm{CF}$ is everywhere larger than 1.2) show largely uniform $\mathrm{GF}_{\mathrm{H} 2 \mathrm{O}}$ and $\mathrm{GF}_{\mathrm{CO}}$ distribution with cloud factor (no correlation) up to $\mathrm{CF}=1.5$ or even 1.6 (Figure $11 \mathrm{C})$, but very doubtful results for $\mathrm{GF}_{\mathrm{OCS}}$ and $\mathrm{GF}_{\mathrm{SO} 2}$ (Figure 11D). According to Figure 9, $\mathrm{CF}=1.5$ produces a $2.29 \mu \mathrm{m}$ peak radiance of about $5 \mathrm{~mW} /\left(\mathrm{m}^{2} \mathrm{sr} \mu \mathrm{m}\right)$. Measured 2.29-2.30 $\mu \mathrm{m}$ radiances of $5 \mathrm{~mW} /\left(\mathrm{m}^{2} \mathrm{sr} \mu \mathrm{m}\right)$ seem to establish a lower limit of utilizable VIRTISM-IR data, therefore. Tsang et al. (2009) have determined a lower radiance value of 20 $\mathrm{mW} /\left(\mathrm{m}^{2}\right.$ sr $\left.\mu \mathrm{m}\right)$ from their band ratio technique, i.e. by a factor of four larger radiances. Present retrieval results thus indicate that a larger number of measurements can be used to investigate tropospheric $\mathrm{CO}$ and $\mathrm{H}_{2} \mathrm{O}$ variability.

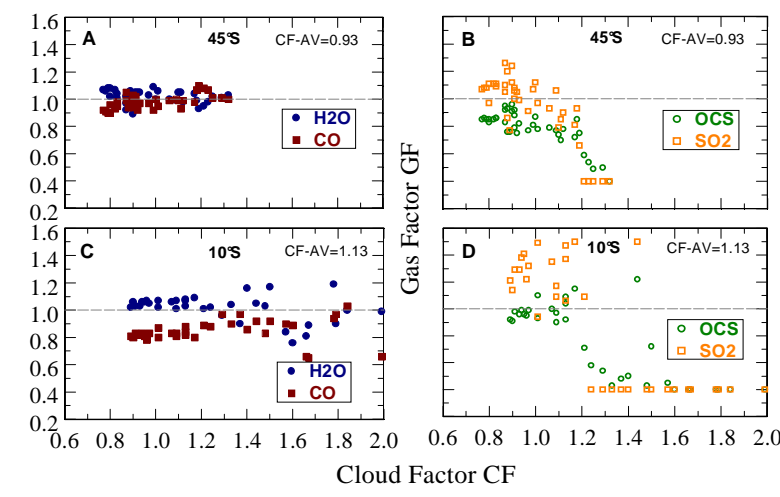

Figure 10. Influence of the total cloud factor $\mathrm{CF}$ on retrieved gas factors. Displays $\mathrm{A}$ and $\mathrm{B}$ : Latitude $45^{\circ} \mathrm{S}$, local time 00:00 $\mathrm{h}$, displays $\mathrm{C}$ and $\mathrm{D}$ : Latitude $10^{\circ} \mathrm{S}$, local time 00:00 h. CF-AV is the average cloud factor.

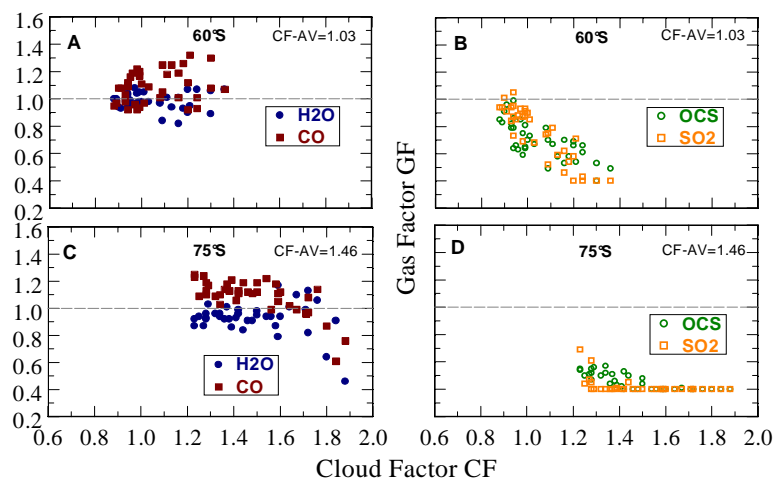

Figure 11. Same as Figure 10, but for $60^{\circ} \mathrm{S}$ (displays $\mathrm{A}$ and $\mathrm{B}$ ) and $75^{\circ} \mathrm{S}$ (displays $\mathrm{C}$ and $\mathrm{D}$ ).

In summary, it is concluded here that $\mathrm{H}_{2} \mathrm{O}$ and $\mathrm{CO}$ abundance retrievals can be performed using all spectra that were measured for cloud factors below 1.5. Neglecting variations of cloud top altitude and cloud mode particle distributions in the upper clouds (modes 1 and 2) with latitude as retrieved by Haus et al. (2014), this would roughly correspond to 2.276 or $1.0 \mu \mathrm{m}$ cloud opacities lower than 52. OCS and $\mathrm{SO}_{2}$, on the other hand, cannot be retrieved for cloud factors larger than 1.2 (2.276 or $1.0 \mu \mathrm{m}$ opacity 42 ) where the measurement signals become too small. These restrictions justify the statement in Section 2 with respect to 
Haus, R., Kappel, D., Arnold, G.. Planetary Space Science xxx, xxx-xxx (2014) Preprint

Figure 2 that operational retrievals are only performed using 20 individual spectra at each grid point of the local time and latitude space that lie in the set $\left\{\mathrm{R}_{\lambda}{ }^{\text {mean* }}, \ldots, \mathrm{R}_{\lambda}{ }^{\text {max* }^{*}}\right\}$, i.e. most cases with very high cloud opacity are excluded from the outset. When retrieved CF values for the remaining spectra exceed 1.2, determined $\mathrm{GF}_{\mathrm{OCS}}$ and $\mathrm{GF}_{\mathrm{SO} 2}$ values are discarded and not further used for averaging purposes. The same holds true for $\mathrm{GF}_{\mathrm{H} 2 \mathrm{O}}$ and $\mathrm{GF}_{\mathrm{CO}}$ in cases of $\mathrm{CF}>1.5$.

Very good fits of measured spectra are achieved when the cloud opacity at $2.27 \mu \mathrm{m}$ is not larger than 50. This is shown in Figure $\underline{12}$ for four latitudes at LT=00:00h. The mean spectrum $\mathrm{R}_{\lambda}{ }^{\text {mean* }}$ is used in each case. Display $\mathrm{B}$ also contains the measured spectrum $\mathrm{R}_{\lambda}{ }^{\text {min }^{*}}$ at $75^{\circ} \mathrm{S}$. It is multiplied by a factor of 10 for better representation. It is obvious that these small and noisy radiances are not suitable to retrieve atmospheric parameters.

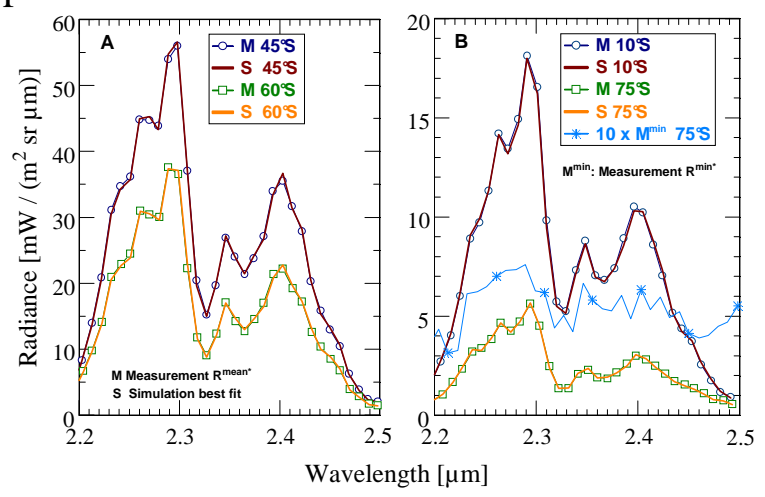

Figure 12. Comparison of averaged VIRTIS-M-IR measurements and simulation results for four latitudes and local time 00:00 h.

Tsang et al. (2010) found some indications for a possible correlation between cloud opacity and sub-cloud water vapor abundance. Excluding spectra where the total cloud opacity exceeds $52\left(\mathrm{GF}_{\mathrm{H} 2 \mathrm{O}}>1.5\right)$ as discussed above, present investigations do not confirm that $\mathrm{H}_{2} \mathrm{O}$ gas factors are correlated with the cloud factor. A possible explanation of observed $\mathrm{GF}_{\mathrm{H} 2 \mathrm{O}}$ variation with latitude is discussed later on in Section 5.1.3.

\subsection{Gas factor error analysis}

It is a general problem in atmospheric remote sensing that not all required atmospheric properties are well known for a given measurement. A few parameters can be retrieved by fitting a simulated to a measured spectrum. The parameters utilized for the simulation of the best fit are interpreted to describe the 'true' physical state of the atmosphere that led to the actually measured spectrum. Other parameters that have an either small impact on the simulated spectrum or that have a very unspecific spectral signature cannot be retrieved from the measurement. However, they must be set to certain values in order to compute the synthetic radiances at all. Deviations of these assumed values from their true states can lead to errors in the simulated spectrum and thus to errors in the retrieved parameters.

Based on recently developed error analysis procedures that characterize the accuracy of retrieved surface parameters from VIRTISM-IR measurements (Kappel et al., 2014), a detailed investigation of gas factor errors in dependence on some interfering atmospheric parameters is performed. To estimate their impact on retrieved gas factors, a fixed synthetic spectrum is computed from a set of parameter values that are regarded as 'true' for this spectrum. One of the interfering parameters is then set to a value that differs from its true value, and the gas factors, along with $\mathrm{CF}$, are retrieved from the synthetic reference spectrum while using this wrong value. Retrieved and corresponding true values are compared. Strong deviations indicate larger retrieval uncertainties of gas factors due to uncertainties in the interfering parameter. This procedure is repeated for a series of wrong values for this interfering parameter that covers its physically expected range, represented by the parameter specific interval $[\mathrm{t}-2 \sigma, \mathrm{t}+2 \sigma]$ centered around a true value $\mathrm{t}$ with a double standard deviation $2 \sigma$.

The retrieval errors, i.e. the maximum percentual deviations of the retrieved from the true values, are shown in Table 1 for a number of interfering parameters. The leftmost column provides a description of the respective interfering parameter. The column 'True value' lists for each of these parameters its 'true' value that has been used to generate 
Haus, R., Kappel, D., Arnold, G.. Planetary Space Science xxx, xxx-xxx (2014) Preprint

the reference spectrum, and the next column ' $2 \sigma^{\prime}$ states its assumed uncertainty. There follow four blocks of columns that are divided into always three sub-columns. Each of these column blocks shows the retrieval errors for one of the studied minor gases, rounded to the nearest whole percent. The three sub-columns for each gas represent the retrieval errors, when the total cloud factor $\mathrm{CF}$ corresponds to $1.0,1.25$, or 1.5 , respectively. In general, the errors increase for increasing $\mathrm{CF}$ as expected. Sometimes, this is not the case, but this only happens, when the quality of the fit is too low (sum of Euclidean norm of difference between reference spectrum and fit, divided by Euclidean norm of reference spectrum above $3 \%$ ) for a certain sub-range of the interfering parameter and the corresponding results are discarded.

Table 1. Percentual retrieval errors of minor gas species due to a $2 \sigma$ variation of atmospheric model parameters. $\mathrm{MF}_{\mathrm{i}}$ : Mode factor of cloud mode $\mathrm{i} ; \mathrm{CT}_{\mathrm{i}} / \mathrm{CB}_{\mathrm{i}} / \mathrm{CC}_{\mathrm{i}}$ : Top/Base/Center altitude of constant peak particle number density of cloud mode $\mathrm{i}$ according to Figure 8; <Temporally varying parameters >: total expected errors of temporally varying parameters (all except continuum) assuming statistical independence. The three sub-columns in the minor gas columns correspond to the total cloud factor 1.0, 1.25, and 1.50, respectively.

\begin{tabular}{|c|c|c|c|c|c|c|c|c|c|c|c|c|c|c|}
\hline \multirow{2}{*}{$\begin{array}{l}\text { Parameter } \\
\mathrm{MF}_{1}\end{array}$} & \multirow{2}{*}{$\begin{array}{c}\text { True value } \\
1\end{array}$} & \multirow{2}{*}{$\frac{2 \sigma}{0.25}$} & \multicolumn{3}{|c|}{$\mathrm{H}_{2} \mathrm{O}$} & \multicolumn{3}{|c|}{$\mathrm{CO}$} & \multicolumn{3}{|c|}{ OCS } & \multicolumn{3}{|c|}{$\mathrm{SO}_{2}$} \\
\hline & & & 1 & 1 & 1 & 0 & 0 & 0 & 0 & 1 & 0 & 0 & 0 & 3 \\
\hline $\mathrm{MF}_{2}$ & 1 & 0.25 & 1 & 2 & 0 & 0 & 0 & 1 & 0 & 3 & 16 & 3 & 20 & 92 \\
\hline $\mathrm{MF}_{2^{\prime}}$ & 1 & 0.25 & 3 & 5 & 6 & 0 & 1 & 1 & 2 & 4 & 5 & 2 & 2 & 1 \\
\hline $\mathrm{MF}_{3}$ & 1 & 0.25 & 9 & 11 & 10 & 1 & 1 & 1 & 5 & 3 & 6 & 2 & 16 & 48 \\
\hline $\mathrm{CT}_{2^{\prime}}$ & $60 \mathrm{~km}$ & $3 \mathrm{~km}$ & 1 & 2 & 4 & 0 & 1 & 1 & 3 & 8 & 22 & 10 & 29 & 100 \\
\hline $\mathrm{CT}_{3}$ & $57 \mathrm{~km}$ & $3 \mathrm{~km}$ & 2 & 3 & 4 & 1 & 2 & 2 & 15 & 25 & 32 & 56 & 111 & 185 \\
\hline $\mathrm{CB}_{1,2^{\prime}, 3}$ & $49 \mathrm{~km}$ & $3 \mathrm{~km}$ & 3 & 5 & 7 & 2 & 3 & 4 & 26 & 48 & 56 & 73 & 173 & 249 \\
\hline $\mathrm{CC}_{2}$ & $65.5 \mathrm{~km}$ & $3 \mathrm{~km}$ & 0 & 0 & 1 & 0 & 0 & 0 & 0 & 1 & 3 & 1 & 3 & 12 \\
\hline $\begin{array}{l}\mathrm{H}_{2} \mathrm{SO}_{4} \\
\text { concentration }\end{array}$ & $80 \%$ & $7.5 \%$ & 28 & 36 & 45 & 3 & 4 & 5 & 26 & 37 & 50 & 28 & 38 & 56 \\
\hline $\begin{array}{l}\text { Continuum } \\
/\left(10^{-29} \mathrm{~cm}^{2}\right)\end{array}$ & 121 & 30 & 4 & 5 & 5 & 3 & 2 & 2 & 30 & 31 & 33 & 27 & 32 & 41 \\
\hline$<$ Temporall & ing param & & 30 & 39 & 47 & 4 & 6 & 7 & 41 & 66 & 86 & 97 & 212 & 347 \\
\hline
\end{tabular}

The first six rows are self explaining. It shall be noted that $\mathrm{CB}_{1,2}, 3$ simultaneously parameterizes the base altitudes of the constant peak particle number density of cloud modes 1, 2', and 3. Variations of $\mathrm{CC}_{2}$ describe an altitude shift of the cloud mode 2 altitude profile. The $\mathrm{H}_{2} \mathrm{SO}_{4}$ concentration of the cloud droplets is assumed to be $75 \%$, but variations are studied in the interval [80\%$7.5 \%, 80 \%+7.5 \%$ ], since a $75-85$ weight- $\%$ solution was recently confirmed to represent the most probable chemical aerosol composition in the lower mesosphere at around $60 \mathrm{~km}$ (Haus et al., 2013). For the present retrieval error analysis, the continuum is assumed to have a constant value within the $2.3 \mu \mathrm{m}$ window, and results for variations of this value up to $25 \%$ are shown in the second last row. The temporally varying parameters (all studied interfering parameters except continuum) are assumed to be statistically independent, and the last row shows the quadratically added temporally varying errors of each column.

In addition to the results shown in the table, it was found that a $\mathrm{GF}_{\mathrm{HF}}$ uncertainty of $25 \%$ around its true value 1.0 leads to marginal retrieval errors (one percentage point at most), as do $\mathrm{CT}_{1}$ variations of $3 \mathrm{~km}$ around $65 \mathrm{~km}$ and reasonable initial value modifications $(\leq 25 \%$ around their true values) for the retrieved minor gases. It was also tested that at $\mathrm{CF}=1.0$, an observation angle of $60^{\circ}$ leads to retrieval errors that are only marginally different from nadir errors, 
Haus, R., Kappel, D., Arnold, G.. Planetary Space Science xxx, xxx-xxx (2014) Preprint

and an increase of $\mathrm{GF}_{\mathrm{CO}}$ from 1.0 to 1.5 has almost no influence on the retrieval errors. However, an increase of $\mathrm{GF}_{\mathrm{H} 2 \mathrm{O}}$ from 1.0 to 1.5 leads to $20 \%$ smaller $\mathrm{H}_{2} \mathrm{O}$ errors and $10 \%$ larger errors for the other gases. If the fullwidth-at-half-maximum of the instrumental response function were $10 \mathrm{~nm}$ and not $17 \mathrm{~nm}$, the $\mathrm{SO}_{2}$ errors would be $10-20 \%$ smaller, and the other gases' errors were almost unaffected.

To estimate retrieval errors that are due to random measurement errors, Gaussian noise with a (realistic) standard deviation of $10^{-4}$ $\mathrm{W} /\left(\mathrm{m}^{2}\right.$ sr $\left.\mu \mathrm{m}\right)$ is added to the synthetic reference spectrum. The described procedure to estimate retrieval errors is repeated 100 times with different realizations of the Gaussian measurement noise. For a fixed interfering parameter, the corresponding retrieval errors are averaged over the 100 noise repetitions, and standard deviations are computed. The maximum percentual deviations of these averages from the true values define the 'noisy' retrieval errors. For $\mathrm{CF}=1.0$, they differ only marginally from the 'noiseless' retrieval errors shown in the $\mathrm{CF}=1.0$ columns in the table. This noise test requires significant computer resources, since the entire procedure to determine the retrieval errors has to be repeated 100 times. Therefore, it is only performed for the $\mathrm{CF}=1.0$ case. The double standard deviations over the noise repetitions are almost independent of the choice of the interfering parameters and amount for $\mathrm{H}_{2} \mathrm{O}$ to $1 \%$ of its true gas factor at $\mathrm{CF}=1.0$. For $\mathrm{CO}$ this expected retrieval error due to measurement noise is $1 \%$, for OCS $4 \%$, and for $\mathrm{SO}_{2} 10 \%$.

This retrieval error analysis reveals that $\mathrm{CO}$ abundances can be retrieved with high confidence even at large cloud opacities. The $\mathrm{H}_{2} \mathrm{O}$ abundance is the second most reliable parameter, and the dominating error source is the uncertainty of the $\mathrm{H}_{2} \mathrm{SO}_{4}$ concentration of the cloud droplets. OCS abundance errors are dominated by uncertainties of the cloud altitude profile and the $\mathrm{H}_{2} \mathrm{SO}_{4}$ concentration. It is obvious that the errors are smallest for lowest cloud opacities. A reliable $\mathrm{SO}_{2}$ abundance retrieval is not possible even at low cloud opacity.

The determined retrieval errors are, on the one hand, possibly underestimated, since not every thinkable interfering parameter can be studied here. Also, measurement and calibration errors can contribute further errors. On the other hand, not each parameter is expected to vary over the full respective studied range, leading to a possible overestimation of the retrieval errors. Also, while some uncertainties of the interfering parameters probably have a more random character, others are possibly systematic and may lead to systematic retrieval errors that would not be obvious in scatterplots such as those shown in Figures 13 and 14. When zonal averages of retrieved parameters are calculated (Section 4.3), it can be expected that the resulting retrieval errors become smaller than those representing maximum percentual deviations of the retrieved from the true values as given in Table 1. However, these retrieval errors well indicate general trends. Only $\mathrm{CO}$ can be reliably retrieved, whereas $\mathrm{SO}_{2}$ cannot be retrieved at all from VIRTIS-M-IR measurements. $\mathrm{H}_{2} \mathrm{O}$ and OCS results have to be cautiously interpreted.

It should be mentioned here that spectrally variable opacity correction ('continuum') values, which are used in the present study, change the individual gas factor retrieval results more or less compared with the case where a constant continuum parameter is considered (cf. Section 3). Maximum gas factor differences occur for OCS where the constant parameter (being usually larger than the variable one in the OCS spectral range, cf. Kappel et al. (2012), Fig. 11) yields up to $15 \%$ higher gas factors. Observed latitudinal trends for all considered gases remain unchanged, however. It is supposed that the use of spectrally variable continuum values that were determined from thousands of spectra originating from highly diverse physical and observational conditions on the planet and the corresponding retrieval results are more reliable. 
Haus, R., Kappel, D., Arnold, G.. Planetary Space Science xxx, xxx-xxx (2014) Preprint

\subsection{Zonal averages of retrieved parameters}

Zonal averages of retrieved parameters are calculated by local time averaging over the night time interval [19:00 $\mathrm{h}, 05: 00 \mathrm{~h}]$ and considering all post-selection spectra $\mathrm{R}_{\lambda}$ mean* $^{*}$ at the local time and latitude grid points over the full mission period as described in Section 2. The corresponding standard deviations of retrieved parameters are a measure of the statistical bandwidth of selected spectra sub-populations (20 at each grid point) and not the standard deviation resulting from the entire measurement ensemble. These standard deviations must not be confused with possible retrieval errors discussed in Section 4.2.

Figure 13 shows the zonal averages of retrieved total cloud factor $\mathrm{CF}$ as a function of latitude (thick solid line). The two thin lines represent the zonal averages of $\mathrm{CF} \pm \sigma_{\mathrm{CF}}$ where $\sigma_{\mathrm{CF}}$ is the cloud factor standard deviation. Single spectrum retrieval results are described by the scatter points. The spectrum population northward of $-40^{\circ} \mathrm{S}$ seems to be significantly sparser, but this is only due to representation, since many scatter points often lie at exactly the same latitude within the $\pm 1^{\circ}$ selection range (cf. Section 2) as a result of the used equal-area data binning scheme. Aspect ratio variations of the data bin edges over the entire sphere should be small. Thus, while in higher latitude regions Lambert azimuthal North/South Pole projections are preferred, Lambert cylindrical projection (standard parallel $30^{\circ}$ ) is used in low latitude regions equatorward of $38.68^{\circ}$. This is the latitude where the aspect ratios of both projections become equal.

There is a strong latitude dependence of the cloud factor that leads to much higher cloud opacities at polar latitudes compared with low and mid latitudes. Minimum opacity occurs between 40 and $55^{\circ} \mathrm{S}$. This was discussed in more detail by Haus et al. (2013; 2014). Although qualitative results are similar with respect to former analyses, quantitative details are slightly different. This is due to the fact that single cloud mode factors $M F_{i}$ and cloud top altitudes $z_{t}$ were retrieved from different parts of infrared spectra in the former investigations, while the present study exclusively determines total cloud factors $\mathrm{CF}$ from the $2.3 \mu \mathrm{m}$ window. This is sufficient for the main purpose of this paper, the retrieval of minor gas abundances in the lower atmosphere. But variation of cloud top altitude with latitude is neglected here. In other words, the initial cloud mode particle distribution with altitude proposed by Haus et al. (2013) is utilized at all latitudes and local times and then modified by retrieved total cloud factors. The southhemispheric average of cloud opacity as retrieved from present analyses is 35.5 compared with the value of 36.5 reported by Haus et al. (2014).

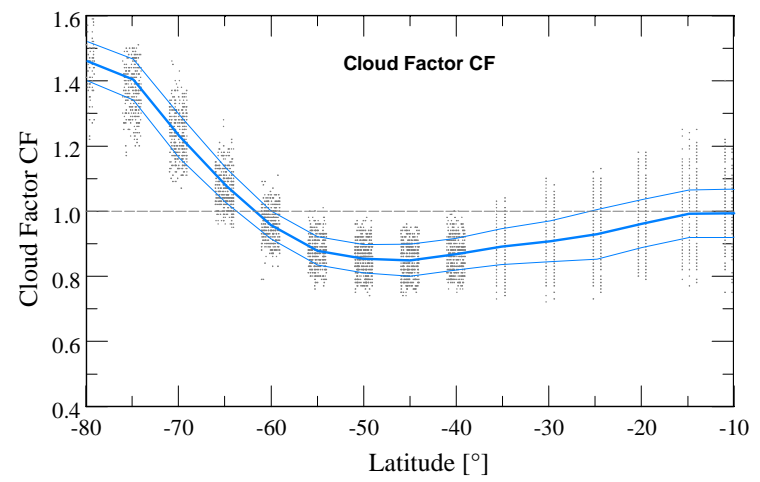

Figure 13. Zonal averages of retrieved total cloud factor CF (thick line) with added and subtracted standard deviation (thin lines) as functions of latitude. Scatter points: Single spectrum retrieval results. Values refer to 1.0 and $2.276 \mu \mathrm{m}$.

Figure 14 displays zonal averages of gas factors $\mathrm{GF}_{\mathrm{H} 2 \mathrm{O}}, \mathrm{GF}_{\mathrm{CO}}, \mathrm{GF}_{\mathrm{OCS}}$, and $\mathrm{GF}_{\mathrm{SO} 2}$ as functions of latitude. The two thin lines in each plot represent the zonal averages of $\mathrm{GF} \pm \sigma_{\mathrm{GF}}$ where $\sigma_{\mathrm{GF}}$ is the gas factor standard deviation. As in case of Figure 13, single spectrum retrieval results are described by the scatter points. Their apparent distribution density change with latitude is explained by the same argument. Recall that individual spectrum retrieval errors may be significantly larger according to the discussion in Section 4.2 with respect to Table 1 .

Zonal averages of water vapor abundances (Figure 14A) exhibit a small decrease from low latitudes to the South Pole. $\mathrm{GF}_{\mathrm{H} 2 \mathrm{O}}$ changes from about 1.02 to 0.92 . The initial 
Haus, R., Kappel, D., Arnold, G.. Planetary Space Science xxx, xxx-xxx (2014) Preprint

factor 1.0 is observed in mid latitudes between 35 and $45^{\circ} \mathrm{S}$. The standard deviation $\sigma_{\mathrm{H} 2 \mathrm{O}}$ increases with increasing equator distance from 0.03 to 0.07 . This can be explained by larger real variations of $\mathrm{H}_{2} \mathrm{O}$ at polar latitudes. Thus, the latitudinal trend may become smaller or larger for individual measurements. Increased polar $\sigma_{\mathrm{H} 2 \mathrm{O}}$ values are also due to the presence of thicker clouds that cause larger retrieval errors.

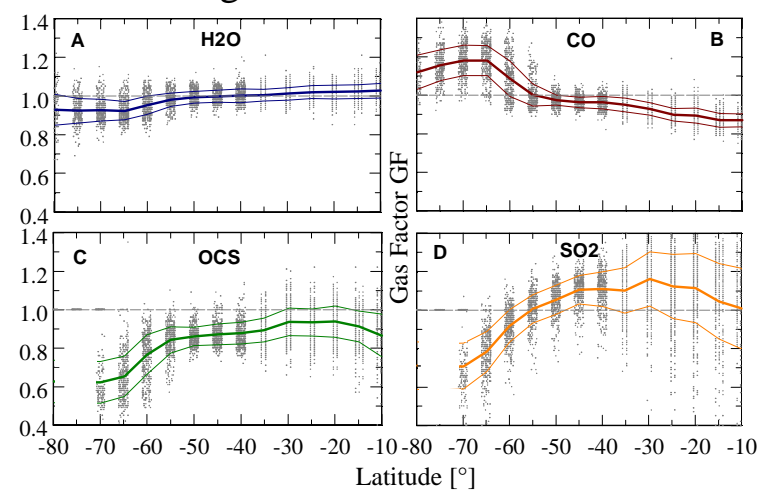

Figure 14. Zonal averages of retrieved gas factors GF (thick lines) with added and subtracted standard deviation (thin lines) as functions of latitude. Scatter points: Single spectrum retrieval results.

Zonal averages of carbon monoxide abundances (Figure 14B) slowly increase from low to mid latitudes. $\mathrm{GF}_{\mathrm{CO}}$ changes from 0.87 at $10^{\circ} \mathrm{S}$ to 0.97 near $50^{\circ} \mathrm{S}$. Poleward of $50^{\circ} \mathrm{S}$, there is a stronger increase up to 1.18 at $65-70^{\circ} \mathrm{S}$ followed by a moderate decrease down to 1.12 at $80^{\circ} \mathrm{S}$. The initial factor 1.0 is observed at mid latitudes near $55^{\circ} \mathrm{S}$. $\sigma_{\mathrm{CO}}$ increases from 0.03 near the equator to 0.09 poleward of $60^{\circ} \mathrm{S}$. Although larger standard deviations occur at high latitudes, the observed equator-to-pole gas factor increase is a real feature with high confidence. This was previously reported by many observers (see Section 5.1.1).

Zonal averages of carbonyl sulfide abundances (Figure 14C) show an opposite trend compared with $\mathrm{CO}$. $\mathrm{GF}_{\mathrm{OCS}}$ slightly increases from 0.81 at $10^{\circ} \mathrm{S}$ to 0.94 near $20^{\circ} \mathrm{S}$ and then decreases poleward of $20^{\circ} \mathrm{S}$ down to 0.62 at $70^{\circ} \mathrm{S}$. The gas factor and standard deviation poleward of $70^{\circ} \mathrm{S}$ are undetermined, since reliable retrievals are not possible here due to cloud factors larger than 1.2 (cf. Figures 11D and 13). The strongest decline is observed between 55 and $65^{\circ} \mathrm{S}$, but this may also be a consequence of retrieval errors due to the increasing cloud factor. Recall from the discussion in Section 4.1 that it may become difficult to retrieve OCS even at cloud factors larger than 1.0 (cf. Figure 11B). The standard deviation $\sigma_{\mathrm{OCS}}$ at most latitudes is higher than for $\mathrm{H}_{2} \mathrm{O}$ and $\mathrm{CO}$ and may reach 0.11 . The observed latitude trend has a lower confidence, therefore. Note that retrieved gas factors for mean radiance spectra $\mathrm{R}_{\lambda}{ }^{\text {mean* }}$ always stay below the initial value of 1.0. Although the depicted OCS latitude trend was reported by previous investigators (see Section 5), it cannot be ruled out that it is generated by large retrieval errors due to uncertainties of the cloud altitude profile and the $\mathrm{H}_{2} \mathrm{SO}_{4}$ concentration of the cloud droplets.

The latitudinal trend of zonal averages of sulfur dioxide abundances (Figure 14D) seems to be similar to that of OCS. A GF $\mathrm{SO}_{2}$ maximum is found at $30^{\circ} \mathrm{S}$ (1.16) and the minimum (0.71) seems to occur at $70^{\circ} \mathrm{S}$ (higher latitude values cannot be retrieved). This would correspond to a $\mathrm{SO}_{2}$ decrease of $38 \%$. The initial factor 1.0 is reached at $10^{\circ} \mathrm{S}$ and near $55^{\circ} \mathrm{S} . \sigma_{\mathrm{SO} 2}$ is largest at low latitudes and attains values up to 0.21 . These large standard deviations and uncertainties due to other possible parameter influences (such as cloud opacity) strongly reduce confidence in a real latitudinal trend of $\mathrm{SO}_{2}$ abundances. In addition, $\mathrm{SO}_{2}$ retrieval from VIRTIS-M-IR spectra are adventurous from the very beginning due to the very weak and narrow spectral signature at around $2.47 \mu \mathrm{m}$ and due to its overlap with those of OCS and $\mathrm{H}_{2} \mathrm{O}$. As a consequence, all $\mathrm{SO}_{2}$ retrieval results are discarded at this point from further discussions.

Figure 15 shows the zonal averages of gas volume mixing ratios $\mathrm{Q}_{\mathrm{H} 2 \mathrm{O}}, \mathrm{Q}_{\mathrm{CO}}$, and $\mathrm{Q}_{\mathrm{OCS}}$ as well as standard deviation (1- $\sigma$ dispersion) bars as functions of latitude. According to Figure 7 , these values are primarily valid at altitudes around $35 \mathrm{~km}$. The initial volume mixing ratios are indicated by broken lines with the values typed above these lines (cf. Figure 5). The curves in the figure are obtained by multiplying the initial mixing 
Haus, R., Kappel, D., Arnold, G.. Planetary Space Science xxx, xxx-xxx (2014) Preprint

ratios at the reference altitude by the retrieved gas factors from Figure 14. Note that the OCS mixing ratio is multiplied by a factor of 10. Recall also again the high uncertainty of OCS results poleward of $70^{\circ} \mathrm{S}$ or already $60^{\circ} \mathrm{S}$. The corresponding values for the hemispheric averages of mixing ratios and mixing ratio standard deviations are given on the right of the box. Hemispheric averages are calculated by weighting the latitude-dependent values with the cosine of latitude.

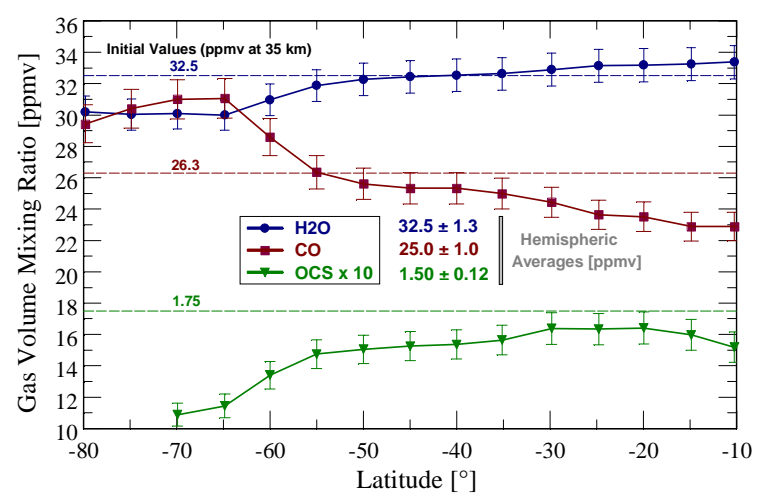

Figure 15. Zonal averages of retrieved gas volume mixing ratios as functions of latitude. See text for further comments.

No attempt was made in the present study to retrieve vertical gradients that differ from the initial mixing ratio altitude profiles. The retrieved zonal average OCS volume mixing ratio at $45^{\circ} \mathrm{S}$ and $35 \mathrm{~km}$ is $1.53 \mathrm{ppmv}$, for example. Since the ratio of initial OCS values at 35 and $33 \mathrm{~km}$ is about 1.71 according to Figure 5, the corresponding retrieved value at $33 \mathrm{~km}$ is about $2.62 \mathrm{ppmv}$. Note however, that this altitude conversion in the sense of a retrieval result is only valid in the vicinity of weighting function maxima, that is, in case of OCS and according to Figure $7 \mathrm{C}$ in the altitude range of about 32$40 \mathrm{~km}$. There is no new retrieval information on OCS volume mixing ratios available at 20 and $60 \mathrm{~km}$, respectively.

Figure 15 and the values for hemispheric averages indicate that the retrieved abundances of $\mathrm{H}_{2} \mathrm{O}$ and $\mathrm{CO}$ quite well verify the latitude-independent initial abundance distribution models for tropospheric altitudes (cf. Figure 5) at mid latitudes between about 35 and $55^{\circ} \mathrm{S}$. Smaller or larger values usually occur at low and high latitudes. This is the consequence of observed latitudinal trends of gas factors. The retrieved gas factors and mixing ratios for OCS, on the other hand, suggest that the initial tropospheric mixing ratio model postulates too high abundances at least near $35 \mathrm{~km}$ where the OCS gas factors are primarily valid.

Zonal averages of $\mathrm{H}_{2} \mathrm{O}$ volume mixing ratios slightly decrease from about $(33 \pm 1)$ ppmv near the equator down to $(30 \pm 2.5) \mathrm{ppmv}$ at polar latitudes. But this $10 \%$ decrease has not a high confidence due to much higher standard deviations at polar latitudes. Zonal averages of $\mathrm{CO}$ mixing ratios increase from $(22.9 \pm 0.8) \mathrm{ppmv}$ at $10^{\circ} \mathrm{S}$ to $(31.1 \pm 2.1)$ ppmv at $65-70^{\circ} \mathrm{S}$. This corresponds to an abundance change of $35 \%$. Even in the worst case within the standard deviation margins this would still result in an increase by about $22 \%$ indicating that the polar enhancement is a real feature. There is an apparent reversal of this trend poleward of $70^{\circ} \mathrm{S}$ leading to a mixing ratio of $(29.4 \pm 2.4) \mathrm{ppmv}$ at $80^{\circ} \mathrm{S}$. Zonal averages of OCS mixing ratios slowly decrease from an average value of $(1.6 \pm 0.2)$ ppmv at low latitudes to $(1.5 \pm 0.13)$ ppmv at $55^{\circ} \mathrm{S}$, but then quickly fall down to $(1.15 \pm$ $0.2)$ ppmv at $65^{\circ} \mathrm{S}$. If the $65^{\circ}$ value was reliable, this would correspond to an overall abundance decline of $28 \%$. But due to the comparatively large standard deviations and the above mentioned difficulties at high latitudes, this percentual estimate has a quite low confidence. Note that the retrieved OCS mixing ratio even at low and mid latitudes is below the initial value of $1.75 \mathrm{ppmv}$.

\subsection{Local time dependence of gas abundances}

The local time dependence of $\mathrm{CO}$, OCS, and $\mathrm{H}_{2} \mathrm{O}$ abundances has been investigated using the mean spectrum $\mathrm{R}_{\lambda}{ }^{\text {mean* }}$ at each grid point of the local time and latitude space and calculating the corresponding abundance standard deviations $\sigma_{\mathrm{i}}$. Recall that $\sigma_{\mathrm{i}}$ is a measure of the statistical bandwidth of the spectra sub-populations that are selected for the retrieval runs. 
Haus, R., Kappel, D., Arnold, G.. Planetary Space Science xxx, xxx-xxx (2014) Preprint

Figure 16 illustrates the local time and latitude dependence of retrieved $\mathrm{CO}$ volume mixing ratios (display $\mathrm{A}$ ) and corresponding standard deviations (display B) at $35 \mathrm{~km}$ altitude. Note that depicted standard deviations refer to real gas concentrations and not to gas factors as shown in Figure 14. The CO abundance at all latitudes varies weakly with local time. Slightly higher abundances (up to $2 \mathrm{ppm}$ (7\%) difference) are observed in the first half of night, especially near $65^{\circ} \mathrm{S}$. Standard deviations $\sigma_{\mathrm{CO}}$ are smaller equatorward of $50^{\circ} \mathrm{S}$ than at higher latitudes where maximum values of 2.4-2.5 ppm occur before midnight at 60$65^{\circ} \mathrm{S}$ and $80^{\circ} \mathrm{S}$. Compared with mean abundance changes, $\sigma_{\mathrm{CO}}$ values are unfortunately in the same order of magnitude. This has to be kept in mind when discussing possible trends with local time. In accordance with Figures 14B and 15, CO abundances attain maximum values between 65 and $70^{\circ} \mathrm{S}$ at all local times, thus differing by about 8-9 ppm (up to 39\%) from equatorial latitudes.

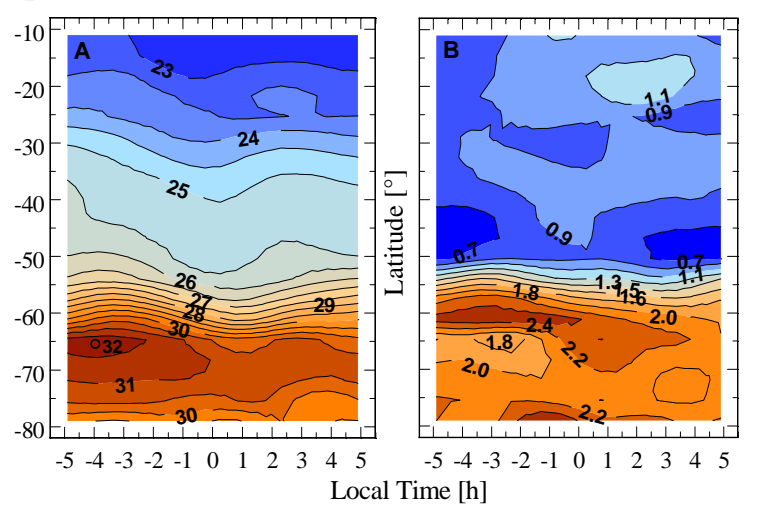

Figure 16. Retrieved $\mathrm{CO}$ mixing ratios (A) and corresponding standard deviations (B) as functions of local time and latitude. Values are given in ppmv. Local time $-5 \mathrm{~h}$ corresponds to 19:00 $\mathrm{h}$.

Observed abundance changes of the other minor gases with local time exhibit similar difficulties. Standard deviations for $\mathrm{H}_{2} \mathrm{O}$ and OCS at many grid points are sometimes even larger by a factor of 1.5-2.0 compared with mean abundance changes. Retrieved local time abundance variations of these constituents are not significant, therefore, and the corresponding plots are not shown here.

\section{Discussion \\ 5.1 Comparison with earlier spectroscopic investigations \\ 5.1.1 Carbon monoxide}

Using NIMS/Galileo measurements in the northern hemisphere of Venus, Collard et al. (1993) were the first who reported on a CO enrichment at polar latitudes by about $35 \%$ compared with low and mid latitudes. Based on the analyses of one selected VEX orbit insertion observation performed by VIRTISM-IR, Tsang et al. (2008) retrieved zonal average $\mathrm{CO}$ mixing ratios at $35 \mathrm{~km}$ altitude of $(23 \pm 2)$ ppmv at equatorial latitudes and $(32 \pm 2)$ ppmv near $60^{\circ} \mathrm{S}$. This corresponds to an increase by $40 \%$. Their results also suggest an overturning in the $\mathrm{CO}$ gradient past $60^{\circ} \mathrm{S}$ with an approximate value of 28 ppm at $80^{\circ} \mathrm{S}$. Tsang et al. (2009) analyzed VIRTIS-M-IR images from the first 18 months of operation in both hemispheres and retrieved zonal averages of $\mathrm{CO}$ mixing ratios at $35 \mathrm{~km}$ altitude of $(22 \pm 3)$ ppmv near the equator and a maximum value of $(32 \pm 3)$ ppmv at $65^{\circ} \mathrm{S}$. A local minimum ( $\left.20 \mathrm{ppmv}\right)$ was observed near $50^{\circ} \mathrm{S}$, however. In addition, the authors reported on some observations where the equator-to-pole $\mathrm{CO}$ gradient was almost absent. Marcq et al. (2008) had analyzed a number of selected VIRTIS-H measurements (44 orbits) on both hemispheres up to $60^{\circ}$ latitude performed during about 300 Earth days in the early phase of the experiment. They determined $\mathrm{CO}$ at $36 \mathrm{~km}$ with a mixing ratio varying from $24 \pm 3 \mathrm{ppm}$ to $31 \pm 2 \mathrm{ppm}$ from the equator to $60^{\circ} \mathrm{S}(\sim 30 \%)$.

Present retrievals utilize all available VIRTIS-M-IR long detector exposure time (LET) measurements recorded over the full mission period of 930 Earth days (1424 spectral images) applying a statistical exploration. Zonal averages of mixing ratios of $(22.9 \pm 0.8) \mathrm{ppmv}$ at $10^{\circ} \mathrm{S},(28.5 \pm 2.1)$ ppmv at $60^{\circ} \mathrm{S},(31.0 \pm 2.1) \mathrm{ppmv}$ at $65^{\circ} \mathrm{S}$, and $(29.4 \pm 2.4)$ ppmv at $80^{\circ} \mathrm{S}$ are determined at $35 \mathrm{~km}$ altitude corresponding to a $\mathrm{CO}$ increase from $10^{\circ} \mathrm{S}$ to $65^{\circ} \mathrm{S}$ of $35 \%$. There is a reversal of this trend poleward of $70^{\circ} \mathrm{S}$. Note that the \pm figures refer to the 
Haus, R., Kappel, D., Arnold, G.. Planetary Space Science xxx, xxx-xxx (2014) Preprint

statistical variability of retrieved abundances. The retrieved mixing ratios and their percentual variation agree very well with previous findings. In contrast to Tsang et al. (2008), the CO abundance maximum is observed at $65^{\circ} \mathrm{S}$ instead of $60^{\circ} \mathrm{S}$, and the $70^{\circ} \mathrm{S}$ value is only slightly smaller. But the authors have pointed out that retrievals from two other (nominal orbit) observations showed this maximum to have a steady value between 60 and $70^{\circ} \mathrm{S}$ with a slight decrease past $70^{\circ} \mathrm{S}$. This is just what is obtained in the present work and what is also in agreement with averaged results of Tsang et al. (2009). Any temporary absence of the equator-topole $\mathrm{CO}$ increase reported in that paper is not detected here, but this may be due to the applied method of statistical exploration of the entire data archive. Retrieval results of Marcq et al.(2008) do not include latitudes poleward of $60^{\circ}$.

The retrieval error analysis performed in Section 4.2 reveals that $\mathrm{CO}$ can be retrieved with high confidence even at large cloud opacities. The percentual error due to temporally reasonably varying atmospheric model parameters at moderate cloud cover $(\mathrm{CF}=1.0)$ does not exceed $4 \%$.

Table 2 summarizes retrieved carbon monoxide volume mixing ratios in the southern hemisphere at $35 \mathrm{~km}$ altitude as obtained by Tsang et al. (2008; 2009), Marcq et al. (2008), and Haus et al. (this work). It clearly demonstrates that present $\mathrm{CO}$ retrieval results very well agree with previous findings. The conversion of percentual $\mathrm{CO}$ retrieval errors due to the variation of atmospheric model parameters (characterized in the last row of Table 1) into absolute ppmv values (see Figure 13 for cloud factor reference) indicates that these errors are usually close to or smaller than the statistical variability of retrieved abundances. This means that the retrieved statistical variability is a good measure of real $\mathrm{CO}$ abundance variations.

Table 2. Retrieved carbon monoxide volume mixing ratios (ppmv) in the southern hemisphere of Venus at $35 \mathrm{~km}$ altitude.

\begin{tabular}{lcccc}
\hline & $\begin{array}{c}\text { Tsang et } \\
\text { al., 2008 }\end{array}$ & $\begin{array}{c}\text { Tsang et } \\
\text { al., 2009 }\end{array}$ & $\begin{array}{c}\text { Marcq et al., } \\
2008^{\text {a) }}\end{array}$ & $\begin{array}{c}\text { Haus et al., } \\
\text { this work }^{\text {b) }}\end{array}$ \\
\hline Minimum at low latitudes $\left(0-20^{\circ}\right)$ & $23 \pm 2$ & $22 \pm 3$ & $23 \pm 3$ & $\begin{array}{c}22.9 \pm 0.8 \\
( \pm 0.5)\end{array}$ \\
Maximum at high latitudes $\left(60-65^{\circ}\right)$ & $32 \pm 2$ & $32 \pm 3$ & $30 \pm 2$ & $\begin{array}{c}31.0 \pm 2.1 \\
( \pm 0.8)\end{array}$ \\
Polar Latitudes $\left(\sim 80^{\circ}\right)$ & 28 & - & - & $\begin{array}{c}29.4 \pm 2.4 \\
( \pm 1.0)\end{array}$ \\
\hline
\end{tabular}

a) Calculated from $36 \mathrm{~km}$ values by use of vertical mixing ratio gradient shown in Figure 5.

b) Values in parentheses in the last column are calculated from percentual CO retrieval errors due to the variation of atmospheric model parameters given in the last row of Table 1 (see also Figure 13 for cloud factor reference). Note that (compared with Table 1) the $1 \sigma$-values are shown here.

The distribution of $\mathrm{CO}$ abundance and standard deviation with local time and latitude (Figure 16) shows three additional features. They were first mentioned by Tsang et al. (2008) and are now verified by using the full VIRTIS-M-IR archive.

First, the $\mathrm{CO}$ abundance seems to be higher by up to $2 \mathrm{ppmv}(7 \%)$ on the dusk side than on the dawn side, especially around $65^{\circ} \mathrm{S}$. This is probably a consequence of photochemistry at cloud top altitudes between 62 and $70 \mathrm{~km}$ where the main $\mathrm{CO}$ source occurs. Studies by Irvin et al. (2008) have indicated enhanced $\mathrm{CO}$ at mesospheric altitudes at the evening terminator compared with the morning terminator. This is what one should expect, since there is no photolysis during night time. But the downwelling of $\mathrm{CO}$ rich air continues overnight and may lead to smaller $\mathrm{CO}$ abundances at $35 \mathrm{~km}$ shortly before sunrise. It must be emphasized once more, however, that the observed 2 ppmv decrease during night and the corresponding standard 
Haus, R., Kappel, D., Arnold, G.. Planetary Space Science xxx, xxx-xxx (2014) Preprint

deviations are in the same order of magnitude.

Second, the $\mathrm{CO}$ abundance maximum with respect to latitude is observed at $65^{\circ} \mathrm{S}\left(5^{\circ}\right.$ poleward compared with Tsang et al., 2008) at early night, while it is located at $70^{\circ} \mathrm{S}$ at late night. Third, midlatitude abundances (40-50 $\left.{ }^{\circ} \mathrm{S}, \quad 25-26 \mathrm{ppmv}\right)$ exhibit smaller standard deviations compared with high latitudes and even smaller variations compared with low latitudes. This third feature is probably also associated with the cloud opacity minimum and smaller retrieval errors at mid latitudes.

\subsubsection{Carbonyl sulfide}

OCS abundance retrievals from VIRTIS-H data (Marcq et al., 2008) showed a latitudinal variation by about $38 \%$, but being anticorrelated with that of $\mathrm{CO}$, that is, lowest values of $(2.5 \pm 1)$ ppmv were detected near $60^{\circ} \mathrm{S}$ and maximum values of $(4 \pm 1) \mathrm{ppmv}$ near the equator. The authors referenced these values to an altitude of $33 \mathrm{~km}$. Corresponding numbers at $35 \mathrm{~km}$ (the altitude of maximum sensitivity according to Figure 7C) are 1.46 and 2.34 ppm, considering the initial altitude profile of OCS shown in Figure 5. Present retrievals at 35 $\mathrm{km}$ yield zonal averages of OCS mixing ratios of about $1.15\left(65^{\circ} \mathrm{S}\right), 1.35\left(60^{\circ} \mathrm{S}\right)$, and 1.60 (low latitudes) ppmv with standard deviations of $0.2 \mathrm{ppmv}$. They confirm the anticorrelated latitude trend with respect to $\mathrm{CO}$, but absolute mixing ratios are somewhat smaller compared with Marcq et al. (2008). The abundance minimum occurs near 65$70^{\circ} \mathrm{S}$, and the latitudinal variation is $28 \%$ (i.e. $10 \%$ less variation than that mentioned above). It should be mentioned that the observed latitudinal trend may be also due to a latitude-dependent change in the vertical OCS gradient, but this was not investigated here.

The retrieval error analysis for OCS shows that the percentual error due to temporally reasonably varying atmospheric model parameters for a single measurement may vary between about 40 and $85 \%$ in dependence on cloud opacity. It is sometimes difficult to retrieve OCS even at cloud factors in the order of 1.0 where the $40 \%$ value occurs. Uncertainties of both cloud top and cloud bottom location as well as uncertainties due to unknown actual $\mathrm{H}_{2} \mathrm{SO}_{4}$ concentration of the cloud droplets dominate the retrieval error. Recall however that zonal averages of minor gas abundances are more reliable than results obtained from a single measurement. Moreover, observed variations in the OCS scatter plot (cf. Figure 14C) even at polar latitudes (large cloud opacity) are smaller than the predicted retrieval errors that are possibly overestimated, therefore. Nevertheless, the retrieved latitudinal trend of OCS abundances has a lower confidence than the observed CO trend.

\subsubsection{Water vapor}

Present retrieval results indicate that zonal averages of $\mathrm{H}_{2} \mathrm{O}$ abundances near $35 \mathrm{~km}$ decrease by about $10 \%$ from $(33.0 \pm 1.0)$ ppmv near the equator down to $(30.0 \pm 2.5)$ ppmv at polar latitudes. Marcq et al. (2008) did not observe a significant latitude trend, their average value is $(31 \pm 2)$ ppmv between 30 and $40 \mathrm{~km}$. The authors stressed, however, that some variability may be possible with slightly dryer conditions (29 ppmv) poleward of $20^{\circ} \mathrm{N}$. Using highresolution Fourier spectra at 1.1-2.5 $\mu \mathrm{m}$ recorded by the Canada-France Hawaii telescope (CFHT) in 1990 and 1991, de Bergh et al. (1995) derived a constant mean $\mathrm{H}_{2} \mathrm{O}$ mixing ratio between 0 and $40 \mathrm{~km}$ of $(30 \pm 10)$ ppmv. Small latitudinal variations of about $\pm 3 \%$ were detected by Bézard et al. (2009) near the surface based on VIRTIS-MIR data from the $1.18 \mu \mathrm{m}$ window. The retrieved absolute $\mathrm{H}_{2} \mathrm{O}$ abundance was (44 \pm 9) ppmv. Recent analyses of VEX/SPICAVIR data by Bézard et al. (2011) however led to a revision of this result and revealed a $\mathrm{H}_{2} \mathrm{O}$ mole fraction of $(30+10 /-5)$ ppmv at 5-25 $\mathrm{km}$ indicating a uniform $\mathrm{H}_{2} \mathrm{O}$ abundance profile below $40 \mathrm{~km}$. The hemispheric average of present retrievals is $(32.5 \pm 1.3)$ 
Haus, R., Kappel, D., Arnold, G.. Planetary Space Science xxx, xxx-xxx (2014) Preprint

ppmv. It is in excellent agreement with previous results.

Present investigations do not confirm that sub-cloud $\mathrm{H}_{2} \mathrm{O}$ abundance variations are correlated with cloud opacity as long as the latter does not exceed 52. Such a correlation was proposed by Tsang et al. (2010) as possible interpretation of retrieval results.

The $\mathrm{H}_{2} \mathrm{O}$ abundance is the second most reliable gas parameter that can be retrieved from VIRTIS-M-IR spectra, but the maximum error may still reach $47 \%$ for large cloud opacities. The dominating error source is the uncertainty of the $\mathrm{H}_{2} \mathrm{SO}_{4}$ concentration of the cloud droplets. But as in case of OCS, this error may be overestimated. Anyway, $\mathrm{H}_{2} \mathrm{O}$ results have to be interpreted with care.

Any latitudinal variation of the $\mathrm{H}_{2} \mathrm{O}$ mixing ratio (if really present) may be associated with spatial and temporal changes in the gaseous $\mathrm{H}_{2} \mathrm{SO}_{4}$ abundances (Butler et al., 2001). $\mathrm{H}_{2} \mathrm{O}$ is a decomposition product of sulfuric acid, which is known to be highly hygroscopic (Tsang et al, 2010). Due to higher atmospheric temperatures at equatorial and mid latitudes at cloud base altitudes below $50 \mathrm{~km}$, trapped water vapor could be easier released from $\mathrm{H}_{2} \mathrm{SO}_{4}$ droplets than at lower polar temperatures leading to larger $\mathrm{H}_{2} \mathrm{O}$ abundances at low latitudes.

\subsubsection{Sulfur dioxide}

$\mathrm{SO}_{2}$ cannot be reliably retrieved from VIRTIS-M-IR spectra. Reported latitudeindependent $\mathrm{SO}_{2}$ abundances in the $35-45 \mathrm{~km}$ altitude range spread out from $(120 \pm 20)$ ppmv (Bertaux et al., 1992) to $180 \mathrm{ppmv}$ (Pollack et al., 1993). Bézard et al. (1993) derived a value of $(130 \pm 40)$ ppmv from CFHT data. Marcq et al. (2008) did not detect any latitude trend, their uniform mixing ratio is also $(130 \pm 50)$ ppmv at 35 $\mathrm{km}$. Present retrieval results seemed to indicate that zonal averages of $\mathrm{SO}_{2}$ abundances near $42 \mathrm{~km}$ decrease by about $30 \%$ from an averaged value of $165 \mathrm{ppmv}$ at low latitudes down to $115 \mathrm{ppmv}$ at polar latitudes, but this strong decline is very doubtful due to the large retrieval errors especially for large cloud optical depths occurring at high latitudes. Thus, a latitudeindependent value of $(130 \pm 50) \mathrm{ppmv}$ is assumed to be a more realistic one to be used in near-future modeling routines.

\subsection{Dynamical context}

The observed latitudinal trends of $\mathrm{CO}$ and OCS can be qualitatively explained by largescale meridional circulation processes and the existence of a Hadley cell. Strong solar heating at equatorial latitudes causes an upward motion of air from tropospheric to mesospheric altitudes. The air is then transported toward the poles where it sinks down before flowing back to the equator.

$\mathrm{CO}$ is primarily produced above the clouds by photolysis of $\mathrm{CO}_{2}$ by solar UV radiation. The downwelling branch of the Hadley cell transports $\mathrm{CO}$ enriched air to the troposphere where $\mathrm{CO}$ is oxidized by chemical reactions involving $\mathrm{SO}_{2}$ and $\mathrm{SO}_{3}$ (Krasnopolsky and Pollack, 1994; Krasnopolsky, 2007). The main OCS source is believed to result from chemical reactions of $\mathrm{CO}$ and $\mathrm{CO}_{2}$ with minerals on the surface, while OCS sinks may include tropospheric reactions with $\mathrm{SO}_{3}$ and $\mathrm{S}$ to form $\mathrm{CO}_{2}$ and $\mathrm{CO}$.

The observed $35 \%$ CO abundance enhancement from equatorial to polar latitudes with maximum values centered at around $65^{\circ} \mathrm{S}$ at $35 \mathrm{~km}$ altitude provides a valuable estimate of the meridional extension of the Hadley cell in the southern hemisphere. Although some of previous investigators (Tsang et al., 2008; Marcq et al., 2008) postulated the maximum of downwelling motion to be located near $60^{\circ} \mathrm{S}$, present results indicate a slightly different position of this maximum at $65-70^{\circ} \mathrm{S}$, and thus, a larger extension of this generic feature of Venus' meridional circulation. This reliable result also well agrees with investigations of Tsang et al. (2009). 
Haus, R., Kappel, D., Arnold, G.. Planetary Space Science xxx, xxx-xxx (2014) Preprint

There are indications of a local night time (or longitudinal) asymmetry of high-latitude $\mathrm{CO}$ abundances near $35 \mathrm{~km}$ with slightly decreasing abundances toward the dawn side. This can be explained by day and night side differences of photochemical processes at cloud top altitudes, but it might also be a consequence of longitudinal variations in the strength of downwelling air motions.

Chemical kinetic modeling (e.g. Krasnopolsky, 2007) and combined studies of chemistry and transport mechanisms using different General Circulation Models (Yung et al., 2009; Marcq and Lebonnois, 2013) have recently added clues for a better understanding of complex interaction structures between chemistry and dynamics in the atmosphere of Venus. It is worth to mention here that the GCM simulations performed by the second group of authors using a passive CO-like tracer yielded maximum tropospheric abundance values only between $70^{\circ}$ and $80^{\circ}$. Thus, present results are very useful for further chemical and dynamical studies. It is beyond the scope of this paper, however, to investigate atmospheric chemical processes and to discuss possible new implications of the results in terms of Venus General Circulation Models.

\section{Summary and conclusions}

A combined radiative transfer and retrieval technique is used to investigate minor gas abundances in the lower atmosphere of Venus based on VIRTIS-M-IR/VEX nightside radiation measurements in the southern hemisphere recorded over the full mission period (April 2006 - October 2008) at long detector exposure times $(\geq 3.3 \mathrm{~s})$. A data selection strategy is applied that is especially useful for statistical exploration of massive data sets. Total cloud factors that scale altitude distributions of particle abundances of the initial cloud model are derived from radiation signatures in the short-wavelength shoulder of the $2.3 \mu \mathrm{m}$ atmospheric transparency window. Minor gas factors that modify the total atmospheric column density of $\mathrm{H}_{2} \mathrm{O}, \mathrm{CO}, \mathrm{OCS}$, and $\mathrm{SO}_{2}$ are subsequently retrieved from the longwavelength shoulder of this window using least-squares best fits for measured VIRTISM-IR radiance spectra. $\mathrm{H}_{2} \mathrm{O}, \mathrm{CO}$, and OCS abundances at $35 \mathrm{~km}$ are then determined by multiplying mixing ratios at this altitude from an initial model by the retrieved gas factors. A wavelength-dependent $\mathrm{CO}_{2}$ opacity correction is considered for the entire spectral window range.

Polar latitudes are covered by much thicker clouds (1 $\mu \mathrm{m}$ opacity in the order of 50) compared with low and mid latitudes. Minimum opacity (30 at $1 \mu \mathrm{m})$ occurs between 40 and $55^{\circ} \mathrm{S}$. The south-hemispheric average of cloud opacity is 35.5 .

Retrieved zonal averages of carbon monoxide (CO) and carbonyl sulfide (OCS) abundances in the southern hemisphere near $35 \mathrm{~km}$ altitude and their percentual variation with latitude well correspond to earlier results reported in the literature. $\mathrm{CO}$ abundance increases from $(22.9 \pm 0.8) \mathrm{ppmv}$ at equatorial latitudes to $(31.0 \pm 2.1) \mathrm{ppmv}$ at $65-70^{\circ} \mathrm{S}(35 \%)$ and then decreases to $(29.4 \pm$ 2.4) $\mathrm{ppmv}$ at $80^{\circ} \mathrm{S}$ where the \pm figures refer to the statistical variability of retrieved abundances. The statistical exploration of the entire VIRTIS-M-IR data archive reveals, that the $\mathrm{CO}$ abundance maximum exists near $65^{\circ} \mathrm{S}$. The observed latitudinal variation of tropospheric $\mathrm{CO}$ is consistent with a Hadley cell-like circulation on Venus where the downwelling branch at high latitudes transports $\mathrm{CO}$ rich air from cloud top altitudes down to the troposphere. Dusk side abundances near $65^{\circ} \mathrm{S}-70^{\circ} \mathrm{S}$ are probably about $7 \%$ (2 ppm) higher than dawn side values, and the maximum with respect to latitude shifts from 65 to $70^{\circ} \mathrm{S}$ overnight. These abundance differences could be explained by the nocturnal break of $\mathrm{CO}_{2}$ photolysis near the cloud tops.

Present retrieval results confirm the anticorrelation of zonal averages of $\mathrm{CO}$ and OCS abundances near $35 \mathrm{~km}$. CO abundances increase from the equator to polar latitudes, but zonal averages of OCS 
Haus, R., Kappel, D., Arnold, G.. Planetary Space Science xxx, xxx-xxx (2014) Preprint

mixing ratio decreases by $28 \%$ from about $(1.60 \pm 0.2)$ ppmv at low latitudes to about $(1.15 \pm 0.2) \mathrm{ppmv}$ at $65^{\circ} \mathrm{S}$. Zonal averages of $\mathrm{H}_{2} \mathrm{O}$ abundances near $35 \mathrm{~km}$ slightly decreases by about $10 \%$ from $(33.0 \pm 1.0)$ ppmv near the equator down to $(30.0 \pm 2.5)$ ppmv at polar latitudes. The hemispheric average of $\mathrm{H}_{2} \mathrm{O}$ abundance is $(32.0 \pm 1.3)$ ppmv. A significant local time dependence of OCS and $\mathrm{H}_{2} \mathrm{O}$ in the lower atmosphere of Venus is not detected.

A detailed analysis of individual spectrum retrieval errors for different atmospheric models is performed. It reveals that the observed latitudinal trend of $\mathrm{CO}$ abundances is reliable (error 4-7\%), while $\mathrm{H}_{2} \mathrm{O}$ and OCS results have lower confidence (errors 30-47\% and $41-86 \%$, respectively). Retrieved $\mathrm{SO}_{2}$ gas factors and abundances with respect to their latitudinal behavior are very doubtful and probably wrong due to large retrieval errors especially at polar latitudes (up to $350 \%)$. A constant value of $(130 \pm 50) \mathrm{ppmv}$ is suggested for future modeling purposes.

Results of this study will be used in the near future to investigate the influence of retrieved minor gas abundances and their possible latitudinal variability on atmospheric radiative properties below the cloud base as an important prerequisite for sophisticated studies on Venus' radiative energy balance.

\section{Acknowledgments}

This work is funded by the German Research Foundation under grant number HA 2887/21. We acknowledge the work of the VIRTIS/VEX team and also the entire Venus Express team of ESA and Astrium, who made the measurement data available that were used in this study.

\section{References}

Allen, D.A., 1990. Venus. IAU Circular No. 4962

Allen, D.A., Crawford, J.W., 1984. Cloud structure on the dark side of Venus. Nature 307, 222-224, http://dx.doi.org/10.1038/307222a0.
Arney, G., Meadows, V.S., Crisp, D., Schmidt, S.J., Bailey, J. et al., 2014. Spatially resolved measurements of $\mathrm{H}_{2} \mathrm{O}, \mathrm{HCl}, \mathrm{CO}, \mathrm{OCS}, \mathrm{SO}_{2}$, cloud opacity, and acid concentration in the Venus nearinfrared spectral windows. J. Geophys. Res. 119(8), 1860-1891, http://dx.doi.org/10.1002/2014JE004662.

Arnold, G., Drossart, P., Piccioni, G., Haus, R., 2011. Venus atmospheric and surface studies from VIRTIS on Venus Express. Proc. SPIE 8154, Infrared Remote Sensing and Instrumentation XIX, 81540W, http://dx.doi.org/10.1117/12.892895.

Arnold, G., Haus, R., Kappel, D., Piccioni, G., Drossart, P., 2012. VIRTIS/VEX observations of Venus: Overview of selected scientific results. J. Appl. Remote Sensing 6, 20 pp.,

http://dx.doi.org/10.1117/1.JRS.6.063580.

Baines, K.H., Bellucci, G., Bibring, J.P., Brown, R.H., Buratti, B.J. et al., 2000. Detection of sub-micron radiation from the surface of Venus by Cassini/VIMS. Icarus 148(1), 307-311,

http://dx.doi.org/10.1006/icar.2000.6519.

Bertaux, J.L., Widemann, T., Moroz, V.I., Ekonomov, A.P., 1992. Vega measurements of $\mathrm{SO}_{2}$ through the atmosphere of Venus: absence of evidence for recent volcanism. Bull. Amer. Astron. Soc. 24, 996.

Bézard, B., de Bergh, C., Crisp, D., Maillard, J.P., 1990. The deep atmosphere of Venus revealed by high-resolution nightside spectra. Nature 345, 508511, http://dx.doi.org/10.1038/345508a0.

Bézard, B., de Bergh, B., Fegley, B., Maillard, J.P., Crisp, D. et al., 1993. The abundance of sulfur dioxide below the clouds of Venus. Geophys. Res. Lett. 20(15) 1587-1590,

http://dx.doi.org/10.1029/93GL01338.

Bézard, B., Tsang, C.C.C, Carlson R.W., Piccioni, G., Marcq, E., Drossart, P., 2009. Water vapor abundance near the surface of Venus from Venus Express / VIRTIS observations. J. Geophys. Res. 114(E00B39), http://dx.doi.org/10.1029/2008JE003251.

Bézard, B., Fedorova, A., Bertaux, J.L., Rodin, A., Korablev, O., 2011. The 1.10- and 1.18- $\mu$ m nightside windows of Venus observed by SPICAV-IR aboard Venus Express. Icarus 216, 173-183, http://dx.doi.org/10.1006/j.icarus.2011.08.025.

Butler, B.J., Steffes, P.G., Suleiman, S.H., Kolodner, M.A., Jenkins, J.M., 2001. Accurate and consistent microwave observations of Venus and their implications. Icarus 154(2), 226-238, http://dx.doi.org/10.1006/icar.2001.6710.

Carlson, R.W., Baines, K.H., Encrenaz, Th., Taylor, F.W., Drossart, P. et al., 1991. Galileo infrared imaging spectroscopy measurements at Venus. Science 253(5027), 1541-1548, http://dx.doi.org/10.1126/science.253.5027.1541. 
Haus, R., Kappel, D., Arnold, G.. Planetary Space Science xxx, xxx-xxx (2014) Preprint

Carlson, R.W., Anderson, M.S., 2011, Absorption properties of sulfuric acid in Venus' infrared spectral window region. EPSC Abstracts 6, 1171.

Collard, A.D., Taylor, F.W., Calcutt, S.B., Carlson, R.W., Kamp, L.W. et al., 1993. Latitudinal distribution of carbon monoxide in the deep atmosphere of Venus. Planet. Space Sci. 41(7), 487494,

http://dx.doi.org/10.1016/0032-0633(93)90031-V.

Cotton, D.V., Bailey, J., Crisp, D., Meadows, V.S., 2012. The distribution of carbon monoxide in the lower atmosphere of Venus. Icarus 217(2), 570-584, http://dx.doi.org/10.1016/j.icarus.2011.05.020.

Crisp, D., Sinton, W.M., Hodapp, K.W., Ragent, B., Gerbault, F. et al., 1989. The nature of the nearinfrared features on the Venus night side. Science 246(4929), 506-509,

http://dx.doi.org/10.1126/science.246.4929.506.

Crisp, D., Allen, D.A., Grinspoon, D.H., Pollack, J.B., 1991. The dark side of Venus: near-infrared images and spectra from the Anglo-Australian observatory. Science 253(5025), 1263-1266,

http://dx.doi.org/10.1126/science.11538493.

de Bergh, C., Bézard, B., Crisp, D., Maillard, J.P., Pollack, J., Grinspoon, D., 1995. Water in the deep atmosphere of Venus from high-resolution spectra of the night side. Adv. Space Res. 15(4), 79-88, http://dx.doi.org/10.1016/0273-1177(94)00067-B.

Drossart, P., Piccioni, G., Adriani, A., Angrilli, F., Arnold, G. et al., 2007. Scientific goals for the observation of Venus by VIRTIS on ESA/Venus Express mission. Planet. Space Sci. 55(12), 16531672, http://dx.doi.org/10.1016/j.pss.2007.01.003.

Haus, R., Arnold, G., 2010. Radiative transfer in the atmosphere of Venus and application to surface emissivity retrieval from VIRTIS/VEX measurements. Planet. Space Sci. 58(12), 1578-1598, http://dx.doi.org/10.1016/j.pss.2010.08.001.

Haus, R., Kappel, D., Arnold, G., 2013. Simultaneous retrieval of temperature profiles and cloud parameters in the northern hemisphere of Venus based on comparative analyses of VIRTIS/VEX and PMV/VENERA-15 radiation measurements. Planet. Space Sci. 89, 77-101,

http://dx.doi.org/10.1016/j.pss.2013.09.020.

Haus, R., Kappel, D., Arnold, G., 2014. Atmospheric thermal structure and cloud features in the southern hemisphere of Venus as retrieved from VIRTIS/VEX radiation measurements. Icarus $232 \mathrm{C}, 232-248$, http://dx.doi.org/10.1016/j.icarus.2014.01.020.

Irvin, P.G.J., de Kok,A., Negrao, A., Tsang, C.C.C., Wilson C.F. et al., 2008. Spatial variability of carbon monoxide in Venus' mesosphere from Venus Express/VIRTIS Visible and Infrared Thermal
Imaging Spectrometer measurements. J. Geophys. Res. 113(E00B01), http://dx.doi.org/10.1029/2008JE003093.

Kamp, L.W., Taylor, F.W., Calcutt, S.B., 1988. Structure of Venus's atmosphere from modelling of night-side infrared spectra. Nature 336, 360-362, http://dx.doi.org/10.1038/336360a0.

Kamp, L.W., Taylor, F.W., 1990. Radiative transfer models of the night side of Venus. Icarus 86(2), 510529 ,

http://dx.doi.org/10.1016/0019-1035(90)90231-W.

Kappel, D., Arnold, G., Haus, R., Piccioni, G., Drossart, P., 2012. Refinements in the data analysis of VIRTIS-M-IR Venus nightside spectra. Adv. Space Res. 50(2) 228-255, http://dx.doi.org/10.1016/j.asr.2012.03.029.

Kappel, D., 2014. MSR, a multi-spectrum retrieval technique for spatially-temporally correlated or common Venus surface and atmosphere parameters. J. Quant. Spectrosc. Rad. Transfer 133, 153-176, http://dx.doi.org/10.1016/j.jqsrt.2013.07.025.

Kappel, D., Haus, R., Arnold, G., 2014. Error analysis for retrieval of Venus' IR surface emissivity from VIRTIS/VEX measurements. Submitted to Planet. Space Sci.

Krasnoplsky, V.A., 2007. Chemical kinetic model for the lower atmosphere of Venus. Icarus 191, 25-37, http://dx.doi.org/10.1016/j.icarus.2007.04.028.

Krasnopolsky, V.A., Pollack, J.B., 1994. $\mathrm{H}_{2} \mathrm{O}-\mathrm{H}_{2} \mathrm{SO}_{4}$ system in Venus' clouds and $\mathrm{OCS}, \mathrm{CO}$, and $\mathrm{H}_{2} \mathrm{SO}_{4}$ profiles in Venus' troposphere. Icarus, 109(1), 58-78, http://dx.doi.org/10.1006/icar.1994.1077.

Marcq, E., Bézard, B., Encrenaz, T., Birlan, M., 2005. Latitudinal variation of $\mathrm{CO}$ and OCS in the lower atmosphere of Venus from near-infrared nightside spectro-imaging. Icarus, 179(2), 375-386, http://dx.doi.org/10.1016/j.icarus.2005.06.018.

Marcq, E., Encrenaz, T., Bézard, B., Birlan, M., 2006. Remote sensing of Venus' lower atmosphere from ground-based IR spectroscopy: Latitudinal and vertical distribution of minor species. Planet. Space Sci. 54(13-14), 1360-1370,

http://dx.doi.org/10.1016/j.pss.2006.04.024.

Marcq, E., Bézard, B., Drossart, P., Piccioni, G., Reess, J.M., Henry, F., 2008. A latitudinal survey of $\mathrm{CO}, \mathrm{OCS}, \mathrm{H}_{2} \mathrm{O}$, and $\mathrm{SO}_{2}$ in the lower atmosphere of Venus: Spectroscopic studies using VIRTIS-H. J. Geophys. Res. 113(E00B07),

http://dx.doi.org/10.1029/2008JE003074.

Marcq, E., Lebonnois, S., 2013. Simulations of the latitudinal variability of CO-like and OCS-like passive tracers below the clouds of Venus using the 
Haus, R., Kappel, D., Arnold, G.. Planetary Space Science xxx, xxx-xxx (2014) Preprint

Laboratoire de Météorologie Dynamique GCM. J. Geophys. Res. 118(10), 1983-1990, http://dx.doi.org/10.1002/jgre.20146.

Meadows, V.S., Crisp, D., 1996. Ground-based nearinfrared observations of the Venus nightside: The thermal structure and water abundance near the surface. J. Geophys. Res. 101(E2), 4595-4622, http://dx.doi.org/10.1029/95JE03567.

Palmer, K.F., Williams, D., 1975. Optical constants of sulphuric acid: Application to the clouds of Venus. Appl. Opt. 14(1), 208-219, http://dx.doi.org/10.1364/AO.14.000208.

Piccioni, G., Drossart, P., Suetta, E., Cosi, M., Ammannito, E. et al., 2007. VIRTIS: The Visible and Infrared Thermal Imaging Spectrometer, ESA Spec. Publ. SP-1295, pp. 1 -27, European Space Agency, Paris.

Pollack, J.B., Dalton, J.B., Grinspoon, D., Wattson, R.B., Freedman, R. et al., 1993. Near-infrared light from Venus' nightside: A spectroscopic analysis. Icarus 103(1), 1-42, http://dx.doi.org/10.1006/icar.1993.1055.

Seiff, A., Schofield, J.T., Kliore, A.J., Taylor, F.W., Limaye, S.S. et al., 1985. Models of the structure of the middle atmosphere of Venus from the surface to 100 kilometers altitude. In: The Venus International Reference Atmosphere, Kliore, A. J., Moroz, V.I., Keating, G.M. (Eds.). Adv. Space Res. 5(11), 1-305 (1985), http://dx.doi.org/10.1016/0273-1177(85)90197-8.

Taylor, F.W., Crisp, D., Bezard, B., 1997. Nearinfrared sounding of the lower atmosphere of Venus. In: Bougher, S.W., Hunten, D.M., Philips, R.J., (Eds.), Venus II: Geology, Geophysics, Atmosphere, and Solar Wind Environment. University of Arizona Press, Tucson AZ, pp. 325-351.

Tsang, C.C.C., Irwin, P.G.J., Wilson, C.F., Taylor, F.W., Lee, C. et al., 2008. Tropospheric carbon monoxide concentrations and variability on Venus from Venus Express/VIRTIS-M observations. J. Geophys. Res. 113(E00B08), 13pp., http://dx.doi.org/10.1029/2008JE003089.

Tsang, C.C.C., Taylor, F.W., Wilson, C.F., Liddell, S.J., Irwin, P.G.J., et al., 2009. Variability of CO concentrations in the Venus troposphere from Venus Express/VIRTIS using a Band Ratio Technique. Icarus 201(2), 432-443, http://dx.doi.org/10.1016/j.icarus.2009.01.001.

Tsang, C.C.C., Wilson, C.F., Barstow, J.K., Irwin, P.G.J., Taylor, F.W. et al., 2010. Correlations between cloud thickness and sub-cloud water abundance on Venus. Geophys. Res. Lett. 37(2), 5 pp., http://dx.doi.org/10.1029/2009GL041770.
Yung, Y.L., Liang, M.C., Jiang, X., Shia, R.L., Lee, C. et al., 2009. Evidence for carbonyl sulfide (OCS) conversion to $\mathrm{CO}$ in the lower atmosphere of Venus. J. Geophys. Res. 114(E00B34), 16pp., http://dx.doi.org/10.1029/2008JE003094.

Zasova, L.V., Moroz, V.I., Linkin, V.M., Khatuntsev, I.V., Maiorov, B.S., 2006. Structure of the Venusian atmosphere from surface up to $100 \mathrm{~km}$. Cosmic Res. 44(4), 364-383, http://dx.doi.org/10.1134/S0010952506040095.

Zasova, L.V., Ignatiev, N.I., Khatuntsev, I., Linkin, V., 2007. Structure of the Venus atmosphere. Planet. Space Sci. 55(12), 1712-1728,

http://dx.doi.org/10.1016/j.pss.2007.01.011. 